\title{
ESSAYS ON FLUCTUATIONS OF THE Crude Oil Price ANd the Economy
}

\author{
A Dissertation \\ Presented to \\ the Faculty of the Graduate School \\ UNIVERSITY of MISSOURI \\ In Partial Fulfillment \\ of the Requirements for the Degree \\ Doctor of Philosophy \\ by \\ JunCHUAN JESSE ZENG \\ Dr. James Isaac Miller, Dissertation Supervisor
}

JULY 2013 
The undersigned, appointed by the Dean of the Graduate School, have examined the dissertation entitled

\section{Essays on Fluctuations of the Crude Oil Price AND THE ECONOMY}

Presented by Junchuan Jesse Zeng

A candidate for the degree of Doctor of Philosophy in Economics

And hereby certify that in their opinion it is worth of acceptance.

James Isaac Miller

Shawn Ni

Vitor Trindade

Athanasios Micheas 
To my grandparents: Yumin Li and Chengshu Gao Xingqin Li and Shuxian Zeng 


\section{ACKNOWLEDGMENTS}

I would like to express my deepest gratitude to my advisor, Dr. James Isaac Miller, for his time and support throughout the research. I would not have been able to finish this dissertation without his patient guidance and detailed instructions. The inspiration and encouragement from him have helped me overcome many difficulties during the process of this work. I am also grateful to my dissertation committee members. Dr. Shawn Ni and Dr. Vitor Trindade offered extremely valuable insights about the research and helped me improve my research skills. Dr. Athanasios Micheas helped me build a solid statistical foundation along the way, and provided beneficial comments for the statistical part of the project.

My gracious appreciation also goes to the Department of Economics and the Kenneth Lay Research Fund at the University of Missouri as well as Dr. Joseph Haslag, the Kenneth Lay Chair in Economics, for the generous support offered through assistantships and the 2012 summer research grant. The financial assistance afforded me the opportunity to continue with my educational pursuits.

Finally, I am highly indebted to my family. My parents, Yuxia Gao and Xianyu Zeng, offered their selfless support during my study. Their love and encouragement have always been with me and never can I express enough my gratitude for them. My wife, Ye Chen, has always been a good listener, unconditional supporter, and considerate companion. She made the days cheerful and deserves all the credit and gratefulness. 


\section{Table of Contents}

Acknowledgments $\quad$ ii

List of Figures $\quad$ vi

List of Tables $\quad$ vii

Abstract viii

1 Introduction 1

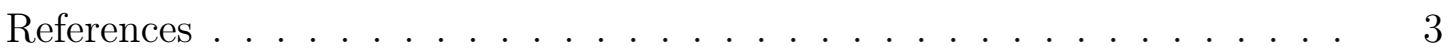

2 How Does Speculation Affect the Oil Price

and Does It Matter to the U.S. Economy? 4

2.1 Introduction . . . . . . . . . . . . . . . . . 5

2.2 A Literature Review . . . . . . . . . . . . . . . . . . 9

2.3 Speculation and the Price of Oil . . . . . . . . . . . . 13

2.4 The Role of the Price of Gold . . . . . . . . . . . . . . . . . . . . 16

2.5 The Structural VAR Model; Data . . . . . . . . . . . . . . . . 22

2.5.1 The drawbacks of the reduced-form VAR and the advantages of the structural VAR . . . . . . . . . . . . . . 23

2.5.2 Components of a crude oil price shock . . . . . . . . . . . 24

2.5.3 The model . . . . . . . . . . . . . . . . . . . . 24

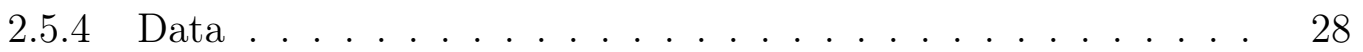


2.6 Empirical Results of the Structural VAR Model . . . . . . . . . . . 28

2.6.1 The historical paths of the structural shocks . . . . . . . . 29

2.6.2 The effects of different structural shocks on oil production, real economic activity, the gold price, and the oil price . . . . . . 31

2.6.3 Forecast error variance decomposition . . . . . . . . . . . 35

2.7 How Does the Speculative Shock Affect Macroeconomic Performance? 36

2.7 .1 The model . . . . . . . . . . . . . . . . . . . . . . . 37

2.7 .2 The results $\ldots \ldots \ldots \ldots \ldots \ldots \ldots$

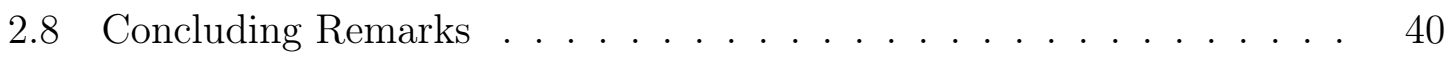

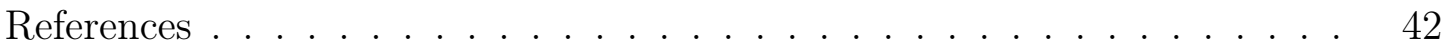

Appendix 2.A: Figures of Chapter $2 \ldots \ldots \ldots \ldots \ldots$

\section{Oil Price and the Stock Returns: Volatility Spillovers and Impacts} of Oil Price Volatility on Stock Returns 51

3.1 Introduction . . . . . . . . . . . . . . . . . . . . 52

3.2 A Literature Review . . . . . . . . . . . . . . . . . . 55

3.3 The Model and Data . . . . . . . . . . . . . . . . . . . . . . . 62

3.3.1 The GARCH-M VAR Model . . . . . . . . . . . . . . . . 62

3.3 .2 The Data . . . . . . . . . . . . . . . . . . . . . 65

3.4 Exploratory Estimation Based on Presumed Break Points . . . . . . . 68

3.4.1 The MLE estimation and the LR test of volatility spillover . . 69

3.4.2 Estimation over the whole sample: 1973:1-2011:7 _ . . . . . 70

3.4.3 Estimation over the subsamples: 1973:1-1988:1, 1988:2-1999:9, and $1999: 10-2011: 7 \ldots \ldots \ldots \ldots \ldots \ldots \ldots \ldots \ldots$

3.4.4 Comments on evidence of structural break . . . . . . . . 74

3.5 Estimation Using the Rolling-Window Technique . . . . . . . . 75

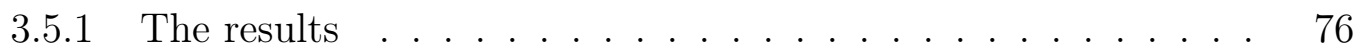


3.5.2 Comments on the empirical evidence on the relationship between oil price volatility and real stock returns . . . . . . . 80

3.6 Concluding Remarks and Comments on Future Work . . . . . . . . 83

References ........................ 85

Appendix 3.A: The Derivation of the Simplified GARCH Specification . . . 89

Appendix 3.B: The Rationale of the LR Test to Isolate the Impact of Oil

Price Volatility on Stock Returns . . . . . . . . . . . . . . . . . 94

Appendix 3.C: Figures and Tables of Chapter $3 \ldots . . . . . . . .995$

4 Conclusion $\quad 101$

References ......................... 103

VITA

104 


\section{List of Figures}

2.1 Plot of real gold price and real oil price, 1973:1-2011:7 . . . . . . . 46

2.2 Estimated structural shocks . . . . . . . . . . . . . . . . 47

2.3 Impulse responses . . . . . . . . . . . . . . . . . . . . . . . . . . . . . 48

2.4 Forecast error variance decomposition . . . . . . . . . . . . . . . . . 49

2.5 Responses of GDP growth and inflation to a speculative shock . . . . 50

3.1 Plot of Real Oil Price, 1973.1-2011.7 . . . . . . . . . . . . . . 95

3.2 Plot of Real Stock Return, 1973.1-2011.7 . . . . . . . . . . . . . 95 


\section{List of Tables}

3.1 Coefficient estimates for the GARCH process, 1973:1 to 2011:7 . . . . 96

3.2 The coefficient estimates for $\Phi(2,1), 1973: 1$ to $2011: 7 \ldots$. . . . . . 96

3.3 Coefficient estimates for the GARCH process, 1973:1 to 1988:1 . . . . 97

3.4 The coefficient estimates for $\Phi(2,1), 1973: 1$ to $1988: 1 \ldots$. . . . . . 97

3.5 Coefficient estimates for the GARCH process, 1988:2 to 1999:9 . . . . 98

3.6 The coefficient estimates for $\Phi(2,1), 1988: 2$ to $1999: 9 \ldots$. . . . . . 98

3.7 Coefficient estimates for the GARCH process, 1999:10 to 2011:7 . . . 99

3.8 The coefficient estimates for $\Phi(2,1), 1999: 10$ to $2011: 7 \quad \ldots$. . . . . . 99

3.9 Estimation results for 1973:1-1987:5 . . . . . . . . . . . . . 100

3.10 Estimation results for 1987:6-2011:7 . . . . . . . . . . . . 100 


\title{
Essays on Fluctuations of the Crude Oil Price AND THE ECONOMY
}

\author{
JunChuAn Jesse Zeng
}

Dr. James Isaac Miller, Dissertation Supervisor

\begin{abstract}
This dissertation studies two major topics related to the crude oil price and the economy. The first topic studied is about the relationship between speculation and the crude oil price and the related implications on the macroeconomic growth and inflation. The second topic is about the relationship between the oil price volatility and the US stock market. It includes two subtopics: i) the volatility spillovers between the crude oil market and the US stock market and ii) the relationship between oil price volatility and real stock returns on the US market.

This dissertation has four chapters, with each of the two major topics studied relatively independently in their respective chapters. In the first chapter, we introduce the background and motivation for the topics studied in this dissertation. Additionally, we also give an overview of the results and important findings.

In the second chapter, we examine the impact of speculative information on the oil price and the corresponding implications on the macroeconomy. We use a structural vector autoregression (VAR) model to decompose the shocks of the crude oil price and use the gold price as a proxy for the speculative information. We argue that using the gold price to account for speculative information is a very informative alternative to the other indicators used in literature. Our results show that speculative information plays a very important role in driving crude oil price shocks; it accounts for about
\end{abstract}


$20 \%$ of the variation of the oil price. Furthermore, we show that speculative shocks to the crude oil price are corrleted to future macroeconomic downturns. We also show that speculative shocks may create inflation pressure, although the effect is not as strong as that on the macroeconomic output growth.

In the third chapter, we use a generalized autoregressive conditional heteroskedasticity $(\mathrm{GARCH})$ specification to model the volatility on both the oil and stock markets and then utilize an extension of the GARCH-M (GARCH in mean) vector autoregression (VAR) model introduced in Elder (2004) to capture the volatility spillover relationship between the two markets and the relationship between the volatility of the oil price and stock returns at the same time. Further, we detect a structural change of the oil price-stock returns relationship near the middle of 1987. A unidirectional volatility spillover from the stock market to the oil market is found to be statistically significant before the break, while a negative relationship between oil price volatility and the conditional mean of stock returns is more pronounced afterwards. We argue that several events happening around the break point are likely to be the causes for the structural change.

In the last chapter, we summarize the work and highlight the important results in this dissertation. In addition, we also discuss possible future research directions. 


\section{$1 \quad$ Introduction}

Research on economic topics related to the crude oil price has been heating up since the pioneering work by Hamilton (1983). From the relationship between the oil price and the macroeconomic performance to that between the oil price and the stock market, from the impact of oil price volatility on economic indicators to the volatility transmissions between the oil market and others, researchers have been actively exploring different aspects of the effects of the oil price fluctuations on the economy.

This dissertation is motivated by the literature on the oil price-economy relationship, and we focus mainly on two topics. First, we follow a battery of studies that focus on the different driving forces of oil price changes and the related implications on the economy to study the effects of speculation on the oil price, and in turn the macroeconomic implications of a speculative oil price shock. Our results show that speculation is a very important component in the fluctuations of the oil price. Moreover, not only does speculation account for a considerable portion of the forecast variation of the oil price, the oil price shocks caused by speculation has a negative pressure on the macroeconomic growth. However, we find that the impact on the inflation level is not as pronounced.

Second, we focus on the interactions between the oil market and the stock market

in the US. We study two aspects of the oil price-stock returns relationship, of which one is about the volatility spillovers between the markets, and the other is about how oil price volatility affects the oil stock returns level. The model we build allows us 
to examine volatility spillovers and the oil volatility-stock returns relationship at the same time. Further, we use a rolling-window technique to identify a structural break. Our results show that there is a well pronounced structural break between May and June of 1987 and the oil price-stock returns relationship behaves quite differently before and after. Before May 1987, there was a significant unidirectional volatility spillover from the stock market to the oil market; however, the oil price volatility did not significantly reduce the overall stock returns. In contrast, after June 1987, it is shown that the volatility spillover between markets vanished, but an increase in oil price volatility likely results in a decline in stock returns. The potential causes of the structural break are also discussed.

This dissertation contributes to the current literature in the following aspects. First, it complements the current literature on the decomposition of oil price shocks and expands the understanding about the oil price changes and the related macroeconomic outcomes. Second, it provides a new angle of looking at the oil price-stock returns relationship, and the detected structural break in 1987 offers a more complete understanding of the relationship. 


\section{References}

Hamilton, J. D. (1983). Oil and the Macroeconomy since World War II. The Journal of Political Economy, 91, 228-248. 


\title{
$2 \quad$ How Does Speculation Affect the Oil Price and Does It Matter to the U.S. Economy?
}

\begin{abstract}
In this chapter, we examine the impact of speculative information on the oil price and the corresponding implications on the macroeconomy. We use a structural vector autoregression (VAR) model to decompose the shocks of the crude oil price and use the gold price as a proxy for the speculative information. We argue that using the gold price to account for speculative information is a very informative alternative to the other indicators used in literature. Our results show that speculative information plays a very important role in driving crude oil price shocks; it accounts for about $20 \%$ of the variation of the oil price. Furthermore, we show that speculative shocks to the crude oil price are corrleted to future macroeconomic downturns. We also show that speculative shocks may create inflation pressure, although the effect is not as strong as that on the macroeconomic output growth.
\end{abstract}

Keywords: Oil Price, Speculation, Gold Price, Macroeconomy

JEL Classification Numbers: Q43, Q48, D84 


\subsection{Introduction}

The relationship between the crude oil price and macroeconomic performance has long been a topic of debate. Hamilton (1983) showed that the oil price increases significantly predict macroeconomic downturns. Later, Mork (1989) showed that the relationship between the oil price and the macroeconomic performance may not be symmetric in the sense that oil price increases and decreases do not correspond to macroeconomic movements of the same magnitude. In other words, while oil price increases predict macroeconomic troughs, oil price decreases fail to generate macroeconomic booms. Bernanke et al. (1997), on the other hand, studied the monetary transmission mechanism of an oil price innovation, and they argued that the monetary policy was what affected the macroeconomy after an oil price shock.

Others found that oil price shocks are driven by different factors, and the macroeconomic implications will be different depending upon which factors are driving the oil price disturbances. Among them, Kilian (2009) provided an innovative angle and a useful toolbox to investigate the underlying factors that drive oil price disturbances, and he showed that the driving forces he identified have different implications on macroeconomic indices. Kilian (2009) features a structural VAR model to decompose an oil price shock into three different orthogonalized structural shocks related to the supply and demand sides of crude oil, for which the names are: the oil supply shock, the aggregate demand shock, and the oil-specific demand shock (or the precautionary demand shock). The definition of the oil-specific demand shock is vague, notwithstanding the detailed discussion on this term in the paper. The term fails to provide information in several key aspects. First, the term "oil-specific demand shock", unlike the other shocks introduced in that paper, is defined as the remainder of an oil price shock after accounting for the other shocks. Second, the driving force of the oilspecific demand shock is not clear. Although Kilian (2009) argued that it is related 
to consumers' precautionary demand of crude oil in fear of future shortfalls of oil supply, it is still arguable whether this shock stems solely from the precaution, or from something else. Using those decomposed shocks, Kilian (2009) also investigated the relationships between macroeconomic indicators and the different structural shocks. He found that the oil-specific demand shock is important in that it has significant relationship with the macroeconomy. However, with the questions associated with the oil-specific demand shock remaining unanswered, or at least not well answered, the relationships between this shock and the macroeconomic indicators need to be studied in a better defined context.

In this chapter, we aim to make improvements on the model introduced by Kilian (2009). With supportive evidence that speculative information plays a significant role in determining commodity prices, we further study oil price shocks, especially the oil-specific demand shock associated with oil price innovations. Using a modified structural VAR specification, we show that there is indeed a type of shock that should not be simply attributed to "precautionary demand". Rather, it should be separated from Kilian's oil-specific demand shock and may be attributed to speculative information.

Unlike some recent researchers who use either crude oil inventory level or oil futures prices to account for the speculative information related to the oil price changes, we use the gold price to capture a wider range of speculative information that may affect the oil price. While most studies focus on the speculative information closely related to the oil market, we choose to expand the pool to include the speculative information which is related to other markets and events, and which may affect the oil price and the economy more generally. In this context, to use the gold price, instead of the other oil related indicators, to account for the speculative information that is contained in the oil price fluctuation, we consider the rationale to be as follows. First of all, compared with the crude oil inventory level, the gold price delivers more 
information about financial markets, which is important since crude oil trading is often closely related to financial markets. Second, the fluctuations of the gold price also reflect investors' speculation about economic prospectives, such as inflation and future growth potential. Although some inventory fluctuations do indicate speculative shocks related to financial activities and economic prospectives, there are also inventory changes that reflect other purposes, e.g. national strategic needs. Thus using inventory data risks diluting the ability of capturing speculative information for our purpose. Third, compared with oil futures prices, the gold price serves as a more comprehensive indicator in capturing the information related to speculative trading, which also exists for crude oil. The gold price is an important index in the global investment market, therefore it can reflect a larger range of speculative information in different fields. Given that different financial markets are globally closely related, using the gold price to proxy speculative information is appropriate. In addition, the fundamentals that affect oil spot price and oil futures prices are similar, and that present a potential problem of identification: one cannot claim that a shared component between these series represents speculation. In contrast, using the gold price avoids this problem, since the gold price is considered not to be driven by the same fundamentals that affect the oil price. Therefore, as a common financial indicator, the gold price is considered to have an accurate shot on our target in capturing speculative information related to a large range of speculative information which may affect the price of oil.

We estimate an extended version of the structural VAR model in Kilian (2009), and the estimated results show that positive shocks in speculative information is correlated to increased oil prices. In addition, the impulse response analysis shows that a speculative shock can push up the oil price persistently; the variance decomposition results show that as much as $20 \%$ of the forecast error variance of the oil price can be accounted for by speculative shocks. In addition, using a methodology introduced in 
Miller and Ni (2010), we estimate the impacts of speculative shocks on two macroeconomic indicators, i) the GDP growth rate and ii) the inflation rate. First, we show that a speculative oil price shock almost immediately has a negative impact on GDP growth, and over time, the cumulative effect can be as large as 1\%. Moreover, we also argue that the fact that speculative shocks present downward pressure on GDP growth may help explain the asymmetry in the oil price-macroeconomy relationship previously documented by other studies. Second, we show that the impact of a speculative oil price shock on inflation rate is positive, which is not surprising. However, the magnitude of the cumulative impact is not as large as one might expect, and it implies that a speculative oil price shock does not seem to be the main reason for the inflationary pressure following an oil price disturbance. Moreover, although gold is usually considered as a hedge against inflation, our results suggests that the common portion of the real gold price and the real oil price seem to have limited predictability on inflation.

The rest of this chapter is organized as the following. In Section 2.2, an extensive review on existing literature is presented to help the readers better understand the background and current studies related to this chapter. Section 2.3 discusses the motivations for why it is important to study the impact of speculative information on the oil price, as well as the related implications on the macroeconomic indicators. Section 2.4 introduces the gold price and discusses its legitimacy as a proxy for speculative information. A structural VAR model is introduced in Section 2.5, which discusses the model setup and the data used to estimate it. The structural VAR model is estimated and the empirical results are shown in Section 2.6, where the estimated structural shocks are shown along with the impulse responses. Forecast error variance decomposition results are also presented to illustrate the importance of each structural shock to our variables of interest, particularly the oil price. Section 2.7 is devoted to exploring the relationships between the speculative oil price shock and two 
macroeconomic indicators, GDP growth rate and inflation. Section 2.8 concludes.

\subsection{A Literature Review}

Hamilton (1983) opened the debate on the relationship between the price of crude oil and macroeconomic performance in the United States. His paper, featuring a twovariable VAR model, revealed that there had been a significant inverse relationship between the crude oil price and the macroeconomic output. In particular, he showed that the data from post WWII support the hypothesis that changes of the price of the crude oil Granger-causes the macroeconomic output, namely, the GNP, but not the other way around. Using the model presented in his paper, he effectively explained the economic recessions in the US following the oil price surges by that time.

That paper drew interest from other researchers and not surprisingly, was followed by critiques. Mork (1989) then argued that the relationship between the crude oil price and the macroeconomy may not be symmetric. He estimated Hamilton's model using two oil price series: one corresponding to oil price increases and the other corresponding to oil price decreases. His results showed evidence that only oil price increases have a significant impact on the macroeconomy: crude oil price surges lead to downward movement of output. However, the opposite does not seem to be significantly supported by the data: oil price plunges do not reliably predict economic recoveries.

A body of literature was then precipitated by the work of Mork (1989), which aimed to explore the reasons why asymmetries were associated with the oil pricemacroeconomy relationship. A group of researchers argued that the relationship between the oil price and the macroeconomy is non-linear. Among this type of literature, Lee et al. (1995) claimed that in an oil price disturbance there are two ingredients. The first one captures the information related to oil price forecasts (which they call 
"time-varying conditional variance of oil price change"), and the second one accounts for the deviations from these forecasts (which they call "unanticipated components"). Their results show that a disturbance in the oil price tends to have a bigger impact on an economy where the oil price has been relatively stable, and the impact of a similar oil price disturbance on an economy where the oil price has been relatively volatile tends to be smaller. Another study by Miller and Ni (2011) decomposes an oil price change into an anticipated long-term price change, which is a slow-moving change, and an unanticipated change, which has more volatility. They found that both components of an oil price change are related to output, however in different fashions: for the unanticipated component, both increase and decrease of it lead to decreases in output growth; for the component that is related to the forecasted longterm price change, or the slow-moving change, its effect on the output growth rate is symmetric in sign, meaning that an increase (or a decrease) in this component leads to a decrease (or an increase) for output growth rate, but with different magnitudes. They also stated that although the effect of a forecasted price change has a smaller overall magnitude, it is more influential.

In addition, Hamilton (1996) introduced a term called "net oil price increase" to measure oil price deviations from its "usual" level. Along with Hamilton (2003), it is shown that only a significant deviation from the "usual" level in the near past should be treated as an oil price shock, and this shock is much more important for the macroeconomic output. On the other hand, oil price increases that make up for previous collapses have smaller prediction power on the economy.

Another group of literature argues, in contrast, that there is little evidence supporting the idea that the relationship between the oil price and the macroeconomy is non-linear. Instead, it is the transmission channel, through which the effect of an oil price disturbance flows into the macroeconomy, that causes the asymmetric oil pricemacroeconomy relationship. Bernanke et al. (BGW, 1997) employed DSGE models 
to study the monetary policy by the Fed during oil price fluctuations and the implications of the monetary policy implemented in response to oil price changes. They argued that it was the monetary policy that the Fed adopted during the oil crisis that had direct effect on the macroeconomy. In other words, monetary policy served as a "channel" for the oil price innovations to take effect on the output. However, Kilian and Vigfusson (2009) argued that the results in BGW, as well as a battery of other studies suffered from problems because of data censoring. Their results showed that there were no significant asymmetries associated with the oil price-macroeconomy relationship. Recently, Kilian and Lewis (2011) pointed out that the monetary policy by the Fed during the pre-1987 era was "poorly identified" since the Fed's responses vary for different types of oil price shocks. They also argued that there was "no evidence" showing that the policy tool which Fed was using during the pre-1987 era was responsible for the fluctuations of the economy. Therefore, they claimed that the framework in BGW needed to be modified.

Several studies looked at other perspectives. Lee and Ni (2002) examined the relationship between the oil price and the macroeconomy by looking at industry-level data. They argued that the oil price shocks have different implications for different industries: for industries that depend on oil as inputs, an oil price surge leads to a decline of supply; in contrast, for other industries where the consumption of products depend on the various oil products, an oil price increase implies a longer-run shrink in demand as purchases of products with large consumption of oil products will be postponed due to a higher oil price. In addition, Miller and Ratti (2009) also found a long-run relationship between the oil price and the stock market, but the relationship did not seem to be stable.

As the debates on the relationship between the oil price and the macroeconomy heat up, a growing body of studies has emerged to discuss the factors that potentially drive the oil price innovations. The rationale of these types of studies is that the 
underlying driving forces of oil price shocks may have different implications on the macroeconomy. Among this group, Kilian (2009) introduced a structural VAR model to decompose an oil price innovation into different underlying structural shocks, which are related to different demand and supply factors that were assumed to affect the oil market. He showed that the underlying factors that drive the oil price disturbances provided significant yet different predictions on the macroeconomic output. This study set a foundation for many studies that followed. Kilian and Park (2009) used a similar approach, and found that the stock market, whose performance is usually treated as a signal of the economy, was also related to the oil price, but the link was not always negative. They found that depending on different factors driving the oil price increases, the return on the stock market could be affected positively or negatively.

In the meantime, a body of literature focused on the impacts on the historical oil price changes from the speculative trading information. Kaufmann and Ullman (2009) studied the factors that drive oil price innovations and the channels through which the oil price shocks entered other markets. They studied the oil prices on both spot and futures markets. Based on evidence from different areas in the world where oil originates, they claimed that "market fundamentals initiated a long-term increase in oil prices" and the information related to speculative trading actually causes the prices to increase even further. Additionally, recent research by Lombardi and van Robays (2011) studied the impacts from financial investors (speculators) on the oil price. Again, they focused on the markets for oil futures. By using a structural VAR model, they found evidence that speculation in financial markets play a role in aggravating short-run oil price fluctuations, yet the market fundamentals are the major forces of driving the oil price. Besides looking at factors on the oil futures market, several studies paid attention to speculative information component in oil price shocks by looking at oil inventory data. This is actually not uncommon, given 
that Pindyck (1994) discussed how inventories are related to producer's incentives and then how the inventory level could in turn affect prices. One example is that Kilian and Murphy (2010), following the methodology of Kilian (2009), studied a structural VAR model with an additional variable capturing oil inventory, and showed that the component related to speculative trading information in oil price shocks was responsible for several oil price surges in history. However, their study did not discuss the importance of speculative demand to the economy.

In the next two sections, we present evidence on the relationship between speculative information and the oil price, and why the gold price is a reasonable candidate to proxy the speculative information contained in the fluctuations of the oil price.

\subsection{Speculation and the Price of Oil}

In classic price theories, speculation plays an important role in determining commodity prices. In addition, Hart and Kreps (1986) show that speculation can destabilize commodity prices. Following these theories, the price of crude oil should be subject to the impacts from speculation as well. Moreover, crude oil differs from common consumption goods in the sense that it cannot be renewed and is non-perishable; yet the demand for crude oil is rigid due to the fact that crude oil is a major energy source for global economic development. Therefore, other than being a consumption good, crude oil is also treated as a means of investment and is traded by investors in financial markets. For example, investors may buy crude oil in the hope that its price in the future increases, therefore profitability can be expected. These kinds of purchase/sell activities are motivated by the speculation of investors about the market conditions in the future, given the current information set. Because different speculation gives investors different incentives and thereby change their investment behaviors, the price of oil may be affected by speculation. Hence, speculation should 
logically play a non-ignorable role in determining the price of crude oil.

Speculation can affect the price of crude oil in other scenarios as well. For example, during the recent Syrian unrest and the Iranian nuclear crisis, the oil price surged to the highest point since the summer of 2008 . The disturbance to the crude oil supply is certainly a reason why the crude oil price climbs, since the sanctions imposed on Iran limit the crude oil quantity available in the market, despite the fact that the production of crude oil by Iran might not have been significantly affected. However, based on the fact that the crude oil price started to increase well before the sanctions on Iran, it is clear that speculation helped push up the crude oil price.

First, the riot in Syria happened before the nuclear crisis in Iran, but it should not significantly affect the global supply of oil, as Syria is not a major oil exporting country. However, given that it is a Mideastern country, informed investors trading crude oil saw the possibilities that other oil exporting countries in that region would be affected by Syria's unrest, so they likely predicted higher oil prices in the future and the price of crude oil is pushed up by their trading behavior. This explains why the oil price was bid up well before any oil supply disruption was actually observed.

Second, the sanctions imposed on Iran had an additional impact on the effect caused by immediate supply shortfalls. With speculation that oil supply will be low in the future, investors trading oil predicted lower availability of oil and therefore higher future potential profitability, so that the trading price of oil was increased, reflecting the changes related to speculation.

Other than the example outlined above, the spot oil price can also fluctuate in accordance with investors' beliefs on the value of crude oil, as long as the beliefs are largely accepted. The beliefs are usually formed based on observations of other industries that need crude oil as a crucial input, or sometimes purely based on misinformed knowledge. In fact, There have been several studies looking at how speculation has affected the price of oil. Among those studies, Kaufmann (2011) documented that an 
econometric model based on fundamentals fails to predict crude oil price and speculation indeed affects the price of oil. Kilian and Murphy (2010) also studied the "speculative demand" for oil by means of using oil inventory levels. However, Since crude oil is crucial for economic development, we consider the speculation our model aims to identify to be a more general speculation conducted by investors on a wider range of economic and financial aspects. For example, the speculation in our study differs from the "speculative demand shock" identified in Kilian and Murphy (2010) in two ways: First, as we discussed earlier, the speculative information in inventory data is potentially diluted. Second, the speculation our model aims to identify includes more information related to financial markets but beyond oil-specific causes as well as other relevant information for the oil price, which the "speculative demand shock" in Kilian and Murphy (2010) does not represent well.

The paper by Kilian (2009) introduced the concept of the oil-specific demand shock, which is essentially the residual of an oil price shock after the "oil supply shock" and the "aggregate demand shock" are accounted for. While he studied the oil-specific demand shock for its significance on oil price fluctuations as well as the implications on the macroeconomic performance, the discussion about the shock is very general. In fact, being a residual component itself, there potentially could be multiple different ingredients contained in the oil-specific demand shock. In other words, the defined "oil-specific demand shock", instead of being just one shock, may very well be a hodgepodge of different shocks. Given the argument we presented above, speculation is a legitimate factor to affect the price of crude oil, but it is not explicitly accounted for by the factors in Kilian's study. Hence it is natural to conjecture that the speculative shock is contained in the oil-specific demand shock in Kilian's model setup. We therefore, as an extension to Kilian (2009), further study the residual shock and investigate its components and their respective impacts on macroeconomic indicators. The importance of further studying the ingredients 
contained in the residual shock lies in a couple of aspects. First, it will help us better understand shocks of the crude oil price. With the doubt that the "oil-specific demand shock" may be a mixture of different shocks, it will be helpful to sort out anything that may be misclassified under the "oil-specific demand" term. By doing this, we can have a clearer picture of how the oil price is affected by different factors. Second, it will provide a better understanding of the relationship between the oil price and the macroeconomy. With a further decomposition of the "oil-specific demand shock", we can more accurately account for the impacts on macroeconomic performances from oil price shocks. In addition, corresponding policy implications can also be a possibility. BGW argued that it was the monetary policy by the Federal Reserve after oil price surges that led to macroeconomic downturns. If we have better knowledge about the causes of oil price disturbances, and in turn their macroeconomic implications, we are in a better position when deciding how to, if at all, respond to an oil price shock.

\subsection{The Role of the Price of Gold}

In the previous section, we showed that studying the effect of speculative information on the crude oil price is important. Empirically, there is evidence that crude oil has links to other speculatively traded assets, e.g. stocks. There exist several papers that study the effects of speculatively traded assets on the price of crude oil, and the related implications on the macroeconomy. For example, Miller and Ratti (2009) studied the long-run relationship between the oil price and the stock markets and they discovered several structural breaks associated with the relationship. Using a similar approach introduced in Kilian (2009), Kilian and Park (2009) studied the relationship between the crude oil price and stock market cycles. Their paper shows that the linkage between the oil price and stock prices is different depending on the driving forces of the oil price shocks. In another paper, Kilian and Murphy (2010) 
studied the effects of speculative demand on the oil price through the use of oil inventories. Their rationale lies in a group of studies arguing that crude oil is an asset of which the price and inventory changes imply the shifts in the expectation of traders. In addition, Lombardi and van Robays (2011) examined the speculative effects on the oil price via the channel of oil futures prices. A reason for using oil futures prices as an indicator for speculative information, as they argued, is that oil futures can be used as a tool for hedging against the risks involved in the fluctuations of the oil price and inflation, and therefore prices of oil futures are affected by the speculation conducted about future spot crude oil prices and other economic indicators.

Unlike existing studies, we use an approach that features the gold price in accounting for the information related to speculative trading. Our approach of accounting for speculative information is justifiable, provided the following two major questions are answered: first, is the gold price a legitimate factor to account for speculative information shocks, and second, is the speculative information contained in a gold price shock reasonable account for that in a crude oil price shock?

The answer to the first question involves examinations of the mechanism of how the price of gold is formed. There have been studies aiming to model the price of gold, for example, Abken (1980) and Kaufmann and Winters (1989). Abken (1980) mentioned two types of reactions to the gold price surge and high trading volume in late 1970s. One was that the gold price was driven by mob psychology, i.e. speculation, while the other argues that price fluctuation for gold could be explained by economic fundamentals. While the model presented in Kaufmann and Winters (1989) produces gold price forecasts that are highly correlated with the actual gold price for 16 years leading to that time, "many variables often considered important to the price of gold are ignored." Therefore, it implies that the model might not be well identified. In fact, Gulati and Mody (1982) argued that the gold price was "principally" affected by speculation, at least for the well-known gold price fluctuations during 1972-82, 
when the inflation was high. This implies that the inflation hedging demand for gold by investors also involves significant amount of speculation. In addition, Salant and Henderson (1978) explained how anticipation of government gold auctions can affect the price of gold. Therefore, we have reasons to believe that the price of gold is affected by, not only the usual demand and supply fundamentals, but speculation as well.

If we think about the market fundamentals of gold, the supply is very stable in recent several decades. It is extremely hard to find new gold mines in response to higher market price. Neither should it be easy for the supply of gold to decrease in response to a price decrease, since gold is easily recycled. Therefore, if we assume a perfectly inelastic supply curve for gold, the only market fundamental that drives the price of gold would be demand. However, the demand for gold that stems from consumption needs is very limited, for example, jewelry needs are not likely to play a role that is important to the gold price changes. On the other hand, it is also widely believed that gold is traded as a hedging tool against inflation. However, the study by Ghosh et al. (2004) showed that the inflation-hedging function drives the long-run gold price equilibrium, while other factors like default risk and real interest rate (which can cause speculative behaviors) causes the short-run fluctuations of the gold price. The inflation-hedging component, however, maybe removed by using real gold price, and the long-run effect can also be controlled by enough lags. Therefore, we can argue that innovations in the real gold price fluctuations are mostly driven by speculative trading, which works its effects through the demand channel. Although speculative trading affects the gold price through demand, it should not be treated as a fundamental factor since it is solely based on investors' speculations. Even though rational investors invest in gold because of its function of store of value to hedge against potential future economic or financial situations, the judgment on those situations are extremely difficult. In fact, many judgments are simply conducting 
speculations. Therefore, it is reasonable argue that gold price is affected to a very large extent by speculations, and using gold price to account for information related to speculative trading is appropriate.

The answer to the second question involves some close examinations on the roles of gold and crude oil in financial and investment markets. First, crude oil, as gold, can serve the function of storage of value as well. Lombardi and van Robays (2011) mentioned that crude oil itself can serve as a hedge against potential inflation. Treated as an asset, like gold, the desire of holding crude oil also reflects investors' expectations. Further, Narayan et al. (2010) also showed that there is a predictive relationship between the markets of oil and gold. These views support the point that similar, if not the same, speculation information drives the trading behaviors of crude oil and gold. Moreover, we can safely argue that the fundamentals on the oil market and those on the gold market are so different that if there are some factors that are relevant to both prices, they can not be related to the fundamentals of each. Second, as investment tools, crude oil and gold can potentially hedge against each other, to the extent that they both are assets among investors options. This fact strengthens the point that the speculative information that drives crude oil price is likely to be represented by the gold price. Despite the differences in the scenarios discussed above, the essential implication is that in sufficiently many cases, the trading of crude oil and gold is driven by similar speculative information. Therefore, it is appropriate to use the price of gold to account for the information related to speculation which can potentially affect the oil price.

Figure 2.1 shows the historical paths of real gold prices and real crude oil prices, both of which obtained by deflating the nominal values by price indices ${ }^{1}$. For a better comparison, both series are expressed in natural logs. By the appearance of figure, we can see that the two series show similar trends, despite the fact that occasionally

\footnotetext{
${ }^{1}$ Following conventions, gold prices are deflated by CPI for general goods and oil prices are deflated by PPI for fuels and related products and power.
} 
the movements of the two prices are in opposite directions. There are several facts that can be observed in the figure. Between 1973 and 1975, the gold price fluctuated more dramatically than the oil price. There was a large decline in gold price around 1975/76, while the oil price declined slightly and then recovered. After the significant decline of the price of gold in the mid-1970s, the price of gold surged to recover from previous downturn and then reached a historical high. The oil price remained relatively stable while the gold price recovered and then went up significantly after the gold price surpassed the level before the decline. Around 1980/81, both prices peaked at similar times and then started to go down. The gold price plunged to the level of 1975, and then started to fluctuate with a downward trend till the beginning of the 21st century. However, the oil price, after reaching the peak, gradually went down to a level which is similar to that preceding the surge, before it plunged to a low point in the mid-1980s. The oil price then fluctuated during the late-1980s, before the quick climbing in the early-1990s. It is worth noting, however, during the period of 1987-90, the two series generally moved in opposite directions. Another observation is that starting in 1996/97, both series were going down, but the oil price started to surge back around 1999, while the gold price was still decreasing. Entering the 21st century, both series seem to have similar trends, but there were several small time windows when they were moving in opposite directions. The first one is around 2003, when the oil price decreased but the gold price increased. The second one is 2008, when the oil price decreased and recovered, while the gold price was generally increasing.

These similarities are in favor of the hypothesis that some driving forces of these prices are similar. The similarity of the paths may be explained by the argument that the prices of the two commodities are closely related to similar factors which, as we mentioned above, are not likely to be the market fundamentals. However, in order to make a convincing argument about this hypothesis, we use two different tests to 
further verify our claim.

First, we conduct a test for cointegration between the log real oil price and the $\log$ real gold price series. There are several cointegration tests developed using different methodologies, and for our purposes, we choose to use the trace test that was introduced by Johansen (1988) and Johansen (1991) because of its flexibility. To test for the cointegrating relationship between the two series, we choose the lag order of 2 for simplicity. We also add an intercept term to the cointegrating vector. The test statistics for the null hypotheses that there is no cointegrating relationship and that there is at most one cointegrating relationship are 23.22 and 2.29, respectively. Therefore, at the $5 \%$ significance level, we reject the null for the first case (there is no cointegrating relationship) but fail to reject for the second case (there is at most one cointegrating relationship). These test results lead to the conclusion that there is likely a cointegrating relationship between the oil and gold price series, or, it implies that the two series are linked by some similar market forces.

In addition to the Johansen test conducted above, we also conduct a test that is based on a linear model that regresses the first difference of the real oil price on the first difference of the real gold price. Namely,

$$
\Delta o_{t}=\beta_{0}+\beta_{1} \Delta g_{t}+\nu_{t}
$$

where $\Delta$ is the first-difference operator. Here, $o_{t}$ represents the real oil price at time $t, g_{t}$ represents the real gold price at time $t$, and $\nu_{t}$ represents the error term. The results from ordinary least squares (OLS) reveals that the estimate for $\beta_{1}, \hat{\beta}_{1}$, has a positive sign with a $t$-test $p$-value less than 0.001 . This evidence shows that the movements of the two prices are strongly correlated, which is consistent with the evidence shown in Figure 2.1 that the paths of the gold price and the oil price display very similar trends. 
Indeed, crude oil and gold are often considered to be included in portfolios where each asset is considered to be an potential alternative when returns on others are likely to be low. Among many, Ciner et al. (2010) studied a investment model where such portfolio includes crude oil, gold, stocks, bonds, and dollars as different investment assets. They found that gold and oil generally act as "safe haven" assets for other investments, such as dollars and bonds. Therefore, the link between the gold price and the oil price seems to lie in the functionality of their ability to serve as safe alternative assets for loss aversion investors.

Enough evidence has shown that the oil market and the gold market are clearly linked. However, based on the facts that the gold price is largely driven by speculation and that the oil market and the gold market should have very different fundamentals, we believe that the two markets are linked by factors that are other than fundamentals. In other words, we have sufficient evidence that allows us to consider the gold price as a good proxy for the speculative information on the oil market.

\subsection{The Structural VAR Model; Data}

In this section, we introduce a structural VAR model as an extension to the identification by Kilian (2009), in which the author decomposes an oil price shock into three structural shocks. We argued in earlier sections that the three structural shocks identified therein did not fully characterize oil price shocks; in particular, there are potentially other shocks that could be misclassified under the oil-specific demand shock. Hence, following our discussion about the speculation and the gold price, we modify the model by introducing a new variable into the VAR model, intending to capture speculative shocks.

In the following sections, we introduce our structural VAR model starting with a discussion of different types of VAR models. 


\subsubsection{The drawbacks of the reduced-form VAR and the ad- vantages of the structural VAR}

A reduced-form VAR model treats the vector on the left hand side as the dependent variable so that the matrix of coefficients in front of it is normalized to the identity matrix. This form of VAR is easy to estimate using OLS but it produces estimates for the coefficient matrices that do not identify the structural parameters. The estimated coefficient matrices only show the "total effects" of those potential underlying factors, but fail to provide more information on the structures between these factors or any insights on how the underlying factors should be attributed for the "total effects". In addition, the estimated residuals in a reduced-form VAR are mixtures of several components that each may have very different economic implications. Therefore, reduced-form VAR models, despite the easiness in estimation, suffer from major drawbacks in addressing important economic concerns with residuals that are usually correlated with one another.

The estimation of a structural VAR model, in contrast, aims to recover the underlying structure, that the estimated coefficient matrices as well as the residuals provide better information about the relationships between the different variables in the vector and easily interpretable results based on the structural factors recovered. More often, a structural VAR model is used to decompose the variables in the vector of interest into orthogonalized factors, which are uncorrelated with each other. In this case, because the decomposed factors are uncorrelated with each other, it is possible to forecast the impact of one factor controlling for the rest of factors. Therefore, a structural VAR model provides us with information that is more interpretable, and it is more appropriate to use a structural VAR model to examine the different driving forces of oil price shocks and thereby study the impact of these driving forces on the macroeconomy. 


\subsubsection{Components of a crude oil price shock}

Based on the previous discussions, we design a model aiming to further explore the ingredients potentially contained in the oil-specific demand shock defined by Kilian (2009). We use the definitions of the other two structural shocks introduced by Kilian (2009): the oil supply shock and the aggregate demand shock. To overcome the potential issues we pointed out with Kilian's model, we further decompose the oil-specific demand shock, from which we aim to separate out a shock that is related to speculation. We call this shock the "speculative shock", which reflects its nature of being related to speculative information by investors or speculators that may drive the oil price. After the speculation is accounted for, we call the last shock the "residual shock", instead of giving it a specific name. The reason is that it may still have several different ingredients in it, although we believe that the residual shock should be closely related to the oil-specific demand shock Kilian (2009) intended to capture, as we will discuss later.

Motivated by the four structural shocks we presented above, we introduce our VAR model in the next section.

\subsubsection{The model}

To start with, our VAR model features four components in the vector of interest: the change in oil production ( prod), the real economic activity index (rea) created by Kilian $^{2}$, the real price of gold $(r p g)$, and the real price of oil (rpo). In order to recover the underlying structural factors behind oil price shocks, we specify a structural VAR model as the following:

$$
A z_{t}=\sum_{i=1}^{p} \Phi_{i} z_{t-i}+\epsilon_{t}
$$

\footnotetext{
${ }^{2}$ The real economic activity index was introduced in Kilian (2009), and can be obtained from his personal web site: http://www-personal.umich.edu/^lkilian/paperlinks.html.
} 
where $z_{t}$ is the autoregressive vector containing the four variables that are discussed above. $\Phi_{i}$ 's are the coefficient matrices on the lagged $z$ 's. The matrix $A$ is a lower triangular matrix aiming to characterize the relationship between the structural shocks and the reduced-form shocks. Because of the structure-defining matrix $A$, the residual term in the system, $\epsilon_{t}$, contains shocks that are neither serially nor mutually correlated. Based on the discussion about the components of an oil price shock presented earlier, we intend to capture these uncorrelated structural shocks: the shock associated with the supply of oil (sup), the shock related to the global aggregate demand $(a d)$, the shock representing the changes in speculative information (spec), and a residual shock which is potentially an aggregate of other factors that are not accounted for by the former three shocks (res). The lag order $p$ is set to 24 following the prevailing setup in the literature to account for enough seasonality.

Now that $A$ is a lower triangular matrix, its inverse, $A^{-1}$, is also lower triangular. In particular,

$$
A^{-1}=\left(\begin{array}{cccc}
a_{11} & 0 & 0 & 0 \\
a_{21} & a_{22} & 0 & 0 \\
a_{31} & a_{32} & a_{33} & 0 \\
a_{41} & a_{42} & a_{43} & a_{44}
\end{array}\right)
$$

By this setup, the residual term in the reduced-form VAR equation, $e_{t}$, can be decomposed as $e_{t}=A^{-1} \epsilon_{t}$, or,

$$
\left(\begin{array}{c}
e_{t, \text { prod }} \\
e_{t, \text { rea }} \\
e_{t, \text { rpg }} \\
e_{t, \text { rpo }}
\end{array}\right)=\left(\begin{array}{cccc}
a_{11} & 0 & 0 & 0 \\
a_{21} & a_{22} & 0 & 0 \\
a_{31} & a_{32} & a_{33} & 0 \\
a_{41} & a_{42} & a_{43} & a_{44}
\end{array}\right)\left(\begin{array}{c}
\epsilon_{t, \text { sup }} \\
\epsilon_{t, a d} \\
\epsilon_{t, \text { spec }} \\
\epsilon_{t, \text { res }}
\end{array}\right)
$$

As noted in studies that utilizes structural VAR specification as a decomposition tool, a lower triangular decomposition matrix (in this case, $A^{-1}$ ) implies time se- 
quence assumptions of the structural shocks involved. We use the lower triangular decomposition matrix in the sense that the structural shocks can be assumed to occur in the following order during a time period. First, we assume that the oil supply shock happens exogenously and that the oil production term only contains this information. Second, the real economic activity is assumed to respond to both the oil supply shock as well as the aggregate demand shock within the same time period. These first two assumptions follow directly the discussion in Kilian (2009). Third, the gold price is assumed to potentially respond to the oil supply shock, the aggregate demand shock, as well as a shock that is related to speculative information. It should be noted that although one can argue that gold price may not respond to either the oil supply shock or the aggregate demand shock, i.e. $\alpha_{31}=0$ or $\alpha_{32}=0$, or both, we choose not to impose these restrictions and allow them to be estimated freely. And finally, the oil price change is a result of the innovations from all the three shocks we discussed above as well as from a residual shock that accounts for anything other than those three shocks. We make these latter two assumptions in addition to Kilian's assumptions as the baseline for our model.

It is justifiable that an innovation of speculative information takes place after the oil supply shock and the aggregated demand shock, so that it affects contemporaneously both the gold price and the oil price, but not the oil production or the real economic activity terms. First, it is reasonable to assume that speculative information is formed based on observed various economic factors, e.g. oil production and economic prospectives, even in the pure speculating scenario. Therefore, the speculative shock should be ordered after the oil supply shock and the aggregate demand shock. Second, since the oil production fluctuations are assumed to be driven solely by exogenous factors, e.g. political turmoil, wars, and revolutions, etc., it is reasonable to assume that the oil production does not respond to speculative information within the same time period. It is, however, possible that the oil production is affected by 
speculative information in a delayed fashion through the channel of oil price. For example, with a negative oil supply shock so that the oil production goes down, the oil price may go up. More importantly, after the information about oil production is observed, there will be speculation about the future oil price, which may result in oil price innovations as well, affecting the magnitude of the oil price change. The price signal can then be perceived by the oil producers, and could affects oil production later. Third, there is no theoretical support that real economic activity responds to speculative information within the same time period. Rather, it is natural to consider that the real economic activity is affected by speculative information through channels of oil price and other mechanisms. Therefore, the structural VAR model we construct is a reasonable representation of the mechanism of how the oil price evolves over time.

We want to point out that the speculative shock specified in our model is fundamentally different than the "oil-specific demand shock" concept specified in Kilian (2009), which is argued to represent people's "precautionary demand" because of worrying about future oil supply shortfalls. Generally speaking, the speculative shock defined in our model is driven by motivations involved in speculative trading, which stem from the expectation of higher profitability, or judgments or guesses about future economic prospectives. These motivations are different than the "precautionary demand" for oil and therefore should not be represented by Kilian's "oil-specific demand shock". Given the different driving forces for these two different shocks and given that we use gold price to account for the speculative shock, the "oil-specific demand shock" should be contained in our residual shock and is potentially mixed with other unspecified shocks. It should be emphasized that the residual shock may largely reflect the oil-specific demand shock, as we believe there are few, if at all, factors that affects the oil price other than these shocks. However, given the fact that this is the last shock in our model, which is the remainder after we account for other 
shocks explicitly, we err on the side of being conservative by calling it the "residual shock".

\subsubsection{Data}

The monthly data used for estimating our model date from January 1973 to July 2011. The starting time point is determined by the earliest availability of the crude oil production data, which are obtained from the EIA. The oil production data are constructed as the log differences for the world crude oil production, which are approximately the percentage changes over time. The global real economic activity is proxied by the index created by Kilian (2009), using the Drewry Shipping Index. The gold price data are in real terms, for which the nominal prices are obtained from the World Gold Council, and then deflated by the consumer price index (CPI). ${ }^{3}$ For the oil price, we use the West Texas Intermediate (WTI) oil price obtained from the Federal Reserve Economic Data (FRED) hosted by the St. Louis Federal Reserve Bank, deflated by producer price index (PPI) for fuels and related products and power. Both the gold price and the oil price series are transformed by taking natural $\operatorname{logs}^{4}$

\subsection{Empirical Results of the Structural VAR Model}

To estimate the four-variable structural VAR model specified earlier, we first estimate the reduced-form VAR model using ordinary least squares (OLS) and then

\footnotetext{
${ }^{3}$ It is true that the price of gold in US dollars is subject to the impact of the exchange rate of US dollars on the global exchange market. However, if we assume that the theory of Purchasing Power Parity roughly holds, deflating the nominal price by the CPI is sufficient to adjust the price for the variations of the price of gold in US dollars due to exchange rate fluctuations.

${ }^{4}$ In Kilian (2009), the author used PPI deflated refiner's acquisition cost of imported oil, which is available as early as January 1974, and extended the series backwards for 1973. We use the WTI oil prices for two reasons. First, WTI crude oil price data are directly available for the year of 1973 so that data extrapolation is not necessary. We would like to include the year of 1973 in our study, because it is the year when the control of crude oil price was weakened significantly and the crude oil price started to be much more volatile than before. Second, we compared the log real oil prices constructed by both methods after January 1974, and it turns out that the two series are very similar.
} 
apply the maximum-likelihood methodology to recover the matrix that defines the structure of the residuals, namely, $A$. The computation is done in the software $\mathbf{R}$. The estimated results reveal several important findings on how the structural shocks affect the real price of oil, along with other interesting facts. These findings are discussed, in turn, in the following subsections.

\subsubsection{The historical paths of the structural shocks}

Figure 2.2 shows the estimated historical paths of the four structural shocks: the oil supply shock, the aggregate demand shock, the speculative shock, and the residual shock. Since we use 24 lags in our model, the structural shocks shown are from 1975 to 2011. For better readability, the shocks are averaged to annual frequency by computing the mean of corresponding monthly estimates. As Kilian (2009) noted, these plots show that the oil price shock at a certain point of time can be thought of as the overall effect of these structural shocks.

Compared with the results in Kilian (2009), we see similar results for the oil supply shock during the period of 1978-80. There was no oil supply disruption before 1980, when a sharp decline hit the oil supply because of the Iran-Iraq War, along with other factors including the Iranian Revolution and Saudi Arabia announcing drastic cuts in oil production. Different from Kilian (2009), however, we see fluctuations in the aggregate demand shock rather than persistent positive aggregate demand shocks documented in that paper. Further, the plots show that the speculation is significantly positive in 1979, and after accounting for the speculative shock, the residual shock, which we claim should be closely related to the oil-specific shock, is relatively small. This implies that the strong positive oil-specific shock shown in Kilian (2009) for 1979 is largely driven by speculation, and if there were any effect on the real oil price from the residual shock or the oil-specific demand shock during this time, it would be relatively small. 
Compared with the results in Kilian and Murphy (2010), we can see a similar speculation surge during the late 1970s. However, our results show large fluctuations during early 1980s, while Kilian and Murphy (2010) shows that the inventory-proxied speculation is relatively stable during that time. Further, for the entire decade of 1990s, our results are very similar to what Kilian and Murphy (2010) find. The results, however, seem to be different after 2000. Our results show that there are some large fluctuations of speculation for 2000-05, while Kilian and Murphy (2010) shows that the speculation captured by inventory is relatively stable. This observation, therefore, suggests that there is some information about speculation that the inventory data fail to capture, while it is captured in the gold price.

There are several other findings that need to be noted. First, the oil price plunge around mid-1980s seems to be largely driven by the positive shock on oil supply and stagnant aggregate demand. Although the speculative shock was positive in 1986, it did not seem to affect the oil price collapse, given that other factors were strong. Second, the oil price surge in early-1990s seems to be a result of both negative oil supply shocks as well as high aggregate demand shocks. The negative oil supply shocks naturally follow the first Gulf War, and it seems that the positive shocks of aggregate demand exacerbated the matter. To our surprise, neither speculation nor the residual shock seems to play an important role for that time. This is probably because there were other factors that offset the upward push on speculation that would have been caused by the war. In fact, given the fact that we proxy the speculative shock by the gold price, the steady downward movement of the gold price during that time, which indicates weaker investment speculation or less concern about inflation, is likely the reason why the speculative shock stayed around zero for that period of time. In contrast, the large oil price fluctuation around the millennium seems to be largely driven by the residual shock, while oil supply shortfalls also contributed to the oil price rise for that time. Lastly, the speculative shock and the residual shock seem 
to be the major shocks that caused the oil price surge in 2010-11 despite the positive oil supply shocks, which do not seem to be large enough to cancel the upward push on the oil price.

\subsubsection{The effects of different structural shocks on oil produc- tion, real economic activity, the gold price, and the oil price}

Figure 2.3 shows the impulse responses of oil production, real economic activity, the real gold price, and the real oil price to each of the four structural shocks of one standard error. To avoid potential confusion, the signs of the structural shocks are modified such that they should each logically cause an oil price increase. The 95\% confidence bands for the impulse responses are calculated using the wild bootstrap methodology discussed in Gonçalves and Kilian (2004). We conducted 2000 replications for the bootstrap and the responses are projected for 36 months into the future.

The first column of figures shows the projected responses of the four variables to a shock from oil supply. First, the oil production drops immediately when there is a negative oil supply innovation. However, the negative impact on oil production seems to die out very quickly. The impulse response shows that, roughly about two months later, the impact on oil production starts to fluctuate about zero, and it diminishes as the time horizon extends. This result, in fact, is reminiscent of the findings in several articles, that the effect of an oil supply decline in one area can be offset at least partially by a decrease in oil inventories and/or in some cases, by the increases of oil production in other areas. ${ }^{5}$ Second, a shock in oil supply, however, does not seem to have significant implications on real economic activity. The impulse response plot generally stays close to zero and the $95 \%$ confidence band contains zero for the

\footnotetext{
${ }^{5}$ See, for example, Lombardi and van Robays (2011), Kilian and Murphy (2010), etc.
} 
whole time horizon considered. Third, there seems to be a negative impact from an oil supply shock on the real gold price in the long run, despite the fact that the $95 \%$ confidence band contains zero. While this may not be intuitive at first glance, it can be explained as the following, if we consider gold and oil both are involved in speculative trading and are tools to hedge against each other: When there is an oil supply shock that reduces oil production, investors will form speculative information about future oil production and an oil shortage can be predicted. Therefore, there will be an increased willingness to invest in oil compared to gold, as oil can potentially provide higher returns relative to gold. As a result, the gold price is likely to be depressed. Finally, an oil supply shock will only cause an oil price increase for about 5 months, if any, and the effect will be worn out quickly after about half a year. However, the response is not reliable since the confidence band of $95 \%$ contains zero. In fact, since an oil supply shock does not seem to generate persistent impact on oil production, it is not unusual to observe this plot. This implies that the impact on the oil price from a supply shock is more likely to be short-term.

The second column of figures shows the impulse responses of the four variables in the model to an aggregate demand shock. As the first figure shows, the effect of an aggregate demand shock on the oil production is negligible: the impulse response is merely fluctuating around zero and lies well between the confidence band, which contains zero. Second, an aggregate demand shock does have significant impact on global real economic activity, resulting in a large increase in the real economic activity immediately. Although gradually diminishing in size over time, the impact remains strongly positive for more than a year, and after that it starts to die out. Third, an aggregate demand shock does not cause an increase of the gold price immediately. However, the impact begins to emerge after about half a year, when the gold price is pushed upwards. The impact peaks at about 18 months later, and then begins to fade away slowly. However, the impact is small in magnitude for the whole time 
horizon considered, implying that the impact from an aggregate demand shock on the real gold price is somewhat weak. Lastly, an aggregate demand shock causes the oil price to increase, and the effect is strongly persistent over the 36-month period. This result is reminiscent of what Kilian (2009) finds, and here the impact of an aggregate demand shock on the oil price becomes statistically significant after about three quarters, and remains significant up till 16 months later. Moreover, our results show more persistence of the impact from an aggregate demand shock on the oil price than what is shown in Kilian (2009).

The third column of figures shows the impacts on the four variables from a speculative shock, which is proxied by the gold price. The first figure implies that a speculative shock has little impact on oil production. The plot shows that the impact is fluctuating around zero and the $95 \%$ confidence band created by our bootstrap contains zero for the full 36-month time horizon. This is consistent with our expectation that trading speculation shocks should not have meaningful implications for oil production. Compared with Kilian and Murphy (2010), in which the authors showed a somewhat persistent donward pressure on the oil production, our results seem to be more consistent with intuition. The second figure shows that the impact of a speculative shock on the real economic index starts to take off immediately after the shock and steadily reaches the peak at about one and a half years later, despite temporary retreats and recoveries during the 6-month to 15 -month window. After about two years, the impact starts to gradually shrink in size, with a reluctant plateau between 24 and 30 months later. In contrast, Kilian and Murphy (2010) found that the real economic activity index suffers a downward pressure from a positive speculative shock, but generally not significant. This may be explained as that the speculation in our model is not specific to the oil market, in contrast to that proxied by inventory, which is likely to only represent the speculation on the oil market. In the third figure, we can tell that a speculative shock shows an immediate impact on the gold price and 
the effect is persistent for about one and a half years. After that, the impact steadily decreases in size. However, the plot indicates that the impact is strong and persistent overall for the 36-month time period. This should not be surprising, given that the speculative shocks are proxied by the gold price. The last figure in this column shows us very solid evidence of an upward lift of the oil price from a speculative shock. The size of the impact from a speculative shock on the oil price increases for the first half year and slightly decreases for the next one year or so. The impact then recovers from the retreat and reaches another peak at about 2 years later, and slightly decreases afterwards. Overall, the effect of a speculative shock on the real oil price is immediate and persistent for the 36-month period, and this supports the theory that speculative shocks indeed play a significant role in the oil price fluctuations. In Kilian and Murphy (2010), the impact of speculation on the oil price seems to be larger in size initially, but it dies out very fast. Although our results show a smaller size, but the impact seems to be more persistent. These differences, again, confirms our view that the speculation meausred in our paper is likely to be a more comprehensive definition.

The last column of figures shows the impact of a residual shock, which is closely related to the oil-specific demand shock introduced by Kilian (2009). First, a residual shock does not seem to have strong impact on the oil production. Like that to a speculative shock, the response of the oil production to a residual shock fluctuates around zero for the entire 36-month time period. Second, a residual shock is likely to result in instabilities for the real economic activity, but the impact is not large. Particularly, the impact stays moderately positive for about a year and then reverses sign for another year, before it changes sign again. It implies that a residual shock is likely to cause long-term instability of the real economic activity, despite the small size. Third, a residual shock affects the gold price positively, but initially the effect is merely close to zero for about 18 months. After 18 months, the effect becomes more noticeable and starts to increase in magnitude. If we consider the major driving 
force of the residual shock as the oil-specific demand shock, then it is implied that the oil-specific demand shock actually has some spillover effects on the gold price in the long-run. Finally, a residual shock does have a significant impact on the oil price. The impact takes place immediately after the shock and decreases in size for about 15 months after the shock happens. There is a recovery of the impact at about 16 months later, and it is persistent for the rest of the time horizon considered. Compared with the results here and that in Kilian (2009), we see both similarities and differences. In Kilian (2009), the effect of an oil-specific demand shock is very similar to what we show here, and the initial impact is of a similar size to ours. However, in our plot, the impact of a residual shock on the oil price decreases faster as time goes on, while Kilian's plot shows more persistence of the response. This can likely be explained by two reasons. First, our model allows speculative shock to account for part of the effects that were attributed to Kilian's "oil-specific demand shock", so that our impulse response is mostly smaller than that in Kilian's results. Second, since we see that the speculative shock has a long-term persistent effect on oil price, it implies that the long-term persistence of the response of the oil price to an "oil-specific demand shock" may actually be due to the persistence of investors' speculation.

\subsubsection{Forecast error variance decomposition}

A forecast error variance decomposition shows how each of the underlying structural shocks can be attributed to the forecast error variance of each of the variables in the VAR model (see, for example, Lütkepohl, 2007). With this tool, we can visually check how important each structural shock is in the future variation of each of the variables in the model.

Figure 2.4 shows the forecast error variance decomposition for the four variables contained in our model. Focusing on the effect of the speculative shock, it can be observed that speculative information generally has negligible impact on oil production. 
Oil supply disruptions account for the majority of oil production variations. However, for the rest of the variables in the model, namely, real economic activity, the real price of gold, and the real price of oil, the impact from speculative information is more important. For real economic activity, after 10 months, speculation accounts for about $10 \%$ of its variation, and the percentage increases to over $20 \%$ after 22 months. This implies that the speculative information has a stronger impact on the global economic activity in the longer-term. This does not, however, necessarily mean that speculation has impacts on real economic activity, or the global demand. Given that the real economic indices are created from the shipping index, it may suggest that speculation actually plays a role in affecting the shipping index itself. For the real price of gold, speculation is always the dominant component accounting for its variation. Other shocks generally have little impact on gold price, which is consistent with the expectation that the gold price is not likely to be affected by either the oil supply shock or the aggregate demand shock. For the real price of oil, it seems that both the aggregate demand shock and the residual shock play important roles in explaining its variation. More importantly, we observe that speculative shocks also play a crucial role in accounting for the variation of the real oil price, especially in the longer term. The impact from speculative information starts to emerge after a couple of months and improves in size over time. Speculative shocks account for about $10 \%$ of the variation of the real oil price in half a year and the percentage goes up to as much as $20 \%$ in about 2 years.

\subsection{How Does the Speculative Shock Affect Macroe- conomic Performance?}

In the previous section, we showed that speculative shocks play an important role in the fluctuations of the real oil price. The impact of a speculative shock on the oil 
price is persistently positive, even after several months. Therefore, it is natural to ask the question: how is an oil price shock that is driven by speculative information, if at all, related to the macroeconomic indices? Kilian (2009) examines the effects of decomposed oil price shocks on the growth rate of output as well as the inflation rate using current and lagged oil price shocks as regressors, under the assumption that the shocks are predetermined. On the other hand, Miller and Ni (2011) attempt to correct the potential correlation issues involved. They regress out from the oil price shocks the effects of the lagged macroeconomic indices to obtain the residuals. Therefore, the residuals can be treated as the oil price shocks that are not correlated with the lagged macroeconomic indices. To examine the effect of an oil price shock on the macroeconomic performance, they run regressions of macroeconomic indices on their own lags as well as the obtained residuals. The response functions are then calculated through inverting the AR part of the regression to obtain a series of MA coefficients. ${ }^{6}$ In this section, we follow the spirit of the latter paper to examine the responses of the macroeconomic indices to a speculative shock. In addition, Kilian (2009) argued that the macroeconomic indices respond to oil price shocks within the same period. To allow that, we include the concurrent term of the oil price shock on the right side of equations as well.

\subsubsection{The model}

Before the model is introduced, however, there are a couple of points that need to be noted about the frequency of the data used in the estimation. First, the frequency of the output data is quarterly, so we use three-month averages of the estimated speculative shock to form quarterly speculative shocks so that the frequencies match for these series. Second, although CPI data are available monthly, and the monthly inflation rate can be obtained, we choose to use quarterly data as well. The reason

\footnotetext{
${ }^{6}$ For a detailed discussion on the methodology, please refer to the working paper version, Miller and $\mathrm{Ni}$ (2010).
} 
is twofold. Most importantly, we think the month-to-month changes of CPI may involve too much noise, and the noise contained in monthly inflation can hinder the estimation of our model. Instead, using three-month average of CPI and calculating inflation rate on a quarterly basis reduces such noise so that the estimated results will be more reliable. In addition, converting the inflation data into the same frequency as that for the output growth rate allows us to more easily compare the estimated results.

To examine the effect of a speculative shock, we set up the following model:

$$
\begin{aligned}
& y_{t}=\gamma^{y}+\sum_{h=1}^{q} \kappa_{h}^{y} y_{t-h}+\sum_{j=0}^{q} \delta_{j}^{y} \epsilon_{s p e c, t-j}^{p_{y}}+\mu_{t}^{y}, \\
& \pi_{t}=\gamma^{\pi}+\sum_{h=1}^{q} \kappa_{h}^{\pi} \pi_{t-h}+\sum_{j=0}^{q} \delta_{j}^{\pi} \epsilon_{\text {spec }, t-j}^{p_{\pi}}+\mu_{t}^{\pi},
\end{aligned}
$$

where $y_{t}$ represents the quarterly growth rate of output, $\pi_{t}$ the inflation rate, and $\epsilon_{\text {spec }, t-j}^{p_{y}}$ and $\epsilon_{\text {spec,t-j }}^{p_{\pi}}$ are the purged residuals constructed based on the above stated method, which contains the information of speculative shock that are not correlated with the other regressors in the model. Following the convention in the literature of accounting for adequate seasonality impacts, and yet to keep the model parsimonious, $q=4$ is chosen.

\subsubsection{The results}

The model is consistently estimated using ordinary least squares and the resulted cumulative responses to a speculative shock are shown in figure 2.5. The dash lines indicate the $95 \%$ confidence bands, which are constructed using bootstrap method repeating 10,000 times. $^{7}$

\footnotetext{
${ }^{7}$ For simplicity, the bootstrap method is only applied on equations (2.1) and (2.2), but not on the step to compute the purged speculative shocks. Also, as this bootstrapping methodology is less costly than the wild bootstrapping used earlier in the paper, we choose to increase the number of repititions for better performance.
} 
The top figure shows the cumulative response of the growth rate of GDP to a speculative shock of one unit. Clearly a speculative shock has a persistent downward impact on the GDP growth rate. The negative impact on GDP growth takes place immediately after a speculative shock arises. In addition, the plot also indicates that the cumulative effect of a speculative shock starts to increase in size after a quarter and becomes relatively constant after eight quarters, where it stays close to $-1 \%$. Also, the steeper slope during the first year than that of the second year indicates larger impact size in the first year than the second. After about two years, the impact from an innovation of speculation dies out. It therefore shows that the oil price fluctuations that are driven by speculation have important implications in explaining the growth of macroeconomic output. In the previous section, we show that speculation can account for as much as $20 \%$ of the variation in oil price in the long run, it turns out that when an oil price innovation is driven by speculative information, there will be a downward pressure on the macroeconomic growth.

Furthermore, this result can help us explain the asymmetry associated with the oil price-macroeconomy relationship, which is documented in several studies (e.g. Mork (1989), Miller and Ni (2011), etc.) As we showed previously in this chapter, speculation can be high (positive) when the oil price is either high or low. Based on the results in this section, a positive speculative innovation depresses macroeconomic growth. Therefore, the fact that oil price decreases fail to generate economic booms, or to generate economic booms of similar size, can be explained by the following: If the oil price collapses when the speculation is high, then the potential economic boom because of the oil price decrease can be offset by the downward pressure on the macroeconomic growth that results from high speculation. This could result in a weaker relationship between oil price decreases and macroeconomic booms.

The bottom figure shows the cumulative response of the inflation to a speculative shock of one unit. In contrast to the strong impact on the GDP growth, the impact 
on the inflation rate of a speculative shock does not seem to be as impressive. In the long term, the inflation rate is predicted to be pushed up by a speculative shock in a persistent manner, although the size is relatively small. It implies that the impact from a speculative shock on the inflation, if any, is more visible in the long run. The conventional wisdom is that oil price increases usually lead to inflationary pressures. For that matter, our results imply that speculative shocks may not be the key reason for inflationary pressure following an oil market disturbance, since the $95 \%$ confidence band in the figure well contains zero, and even the $68 \%$ confidence band (not shown) has a lower bound at about zero. The inflation pressure following an oil price increase should likely be attributed to other factors.

\subsection{Concluding Remarks}

In this chapter, we study the impact of speculative information on the crude oil price, and then explore the macroeconomic implications of speculative oil price shocks. We use gold price as an alternative indicator to capture a more comprehensive pool of speculative information affecting crude oil price variations, in contrast to the existing literature. We find that speculative information plays an important role in the fluctuations of the oil price historically. In particular, our results show that speculative shocks may have been an important source for some of the major oil price increases and decreases. And in other cases, speculation seems to play a role in stabilizing the oil price. Using the impulse response analysis, we show evidence that a positive speculative shock has a persistent upward impact on the oil price. Our analysis also shows evidence that a speculative shock on the oil price becomes more important in the long-run, where it could account for as much as $20 \%$ of the oil price variation. We also make comparisons with the results presented in Kilian (2009) and Kilian and Murphy (2010), where we find both similarities and differences, and 
confirm that our speculation measure is a more comprehensive one.

For the macroeconomic implications, we find that speculative shocks have strong negative impacts on the growth of real output. The impact can accrue over time to as large as $1 \%$. More specifically, the negative impact from a speculative shock on U.S. real GDP growth appears immediately, and accumulates in magnitude during the following two years, with faster rate in the first year and slower rate in the second. Our results also show that the inflation rate suffers a potential upward pressure from a positive speculative oil price shock and the size accrues over time in a steady fashion. However, the size of the impact is not very big and the confidence bands indicate that the impact is not reliable. Therefore, even though it is usually claimed that an increase in oil price would create inflationary pressure, the empirical evidence in our study shows that it is not likely that a speculation-driving oil price increase causes a significant inflationary pressure.

Finally, the research underlying this chapter sheds some lights on possible policy suggestions. Although the speculation studied in this chapter is more generally defined, our results do suggest that if the oil market is better regulated to limit the impact from speculation, the macroeconomy growth would be more stable through oil price fluctuations. Recently, President Obama urged congress to "strengthen federal supervision of international oil markets". ${ }^{8}$ This regulation, aiming to "catch speculators who attempt to manipulate markets for their own profit", can potentially help the U.S. achieve more stable macroeconomic growth by reducing oil price fluctuations caused by speculation.

\footnotetext{
${ }^{8}$ See FoxNews.com (2012), Apr. 17, 2012
} 


\section{References}

Abken, P. A. (1980). The Economics of Gold Price Movements. Federal Reserve Bank of Richmond Economic Review.

Bernanke, B. S., Gertler, M., and Watson, M. (1997). Systematic Monetary Policy and the Effects of Oil Price Shocks. Brookings Papers on Economic Activity, 1, $91-142$.

Ciner, C., Gurdgiev, C., and Lucey, B. M. (2010). Hedges and Safe Havens - An Examination of Stocks, Bonds, Oil, Gold and the Dollar. Discussion Paper: Institute for International Integration Studies, 337.

FoxNews.com (2012). Obama Pitches $\$ 52 \mathrm{M}$ Plan to Regulate Oil Markets. Online.

Ghosh, D., Levin, E. J., MacMillan, P., and Wright, R. E. (2004). Gold as an Inflation Hedge? Studies in Economics and Finance, 22, 1-25.

Gonçalves, S. and Kilian, L. (2004). Bootstrapping Autoregressions with Conditional Heteroskedasticity of Unknown Form. Journal of Econometrics, 123, 89-120.

Gulati, I. S. and Mody, A. (1982). International Gold Price Movements, 1972-1982. Economic \& Political Weekly, 17, 1861-1870.

Hamilton, J. D. (1983). Oil and the Macroeconomy since World War II. The Journal of Political Economy, 91, 228-248.

Hamilton, J. D. (1996). This is What Happened to the Oil Price-Macroeconomy Relationships. Journal of Monetary Economics, 38, 215-220.

Hamilton, J. D. (2003). What is an Oil Shock? Journal of Econometrics, 113, 363-398. 
Hart, O. D. and Kreps, D. M. (1986). Price Destabilizing Speculation. The Journal of Political Economy, 94, 927-952.

Johansen, S. (1988). Statistical Analysis of Cointegration Vectors. Journal of Economic Dynamics and Control, 12, 231-254.

Johansen, S. (1991). Estimation and Hypothesis Testing of Cointegration Vectors in Gaussian Vector Autoregressive Models. Econometrica, 59, 1551-1580.

Kaufmann, R. K. (2011). The Role of Market Fundamentals and Speculation in Recent Price Changes for Crude Oil. Energy Policy, 39, 105-115.

Kaufmann, R. K. and Ullman, B. (2009). Oil Prices, Speculation, and Fundamentals: Interpreting Causal Relations among Spot and Futures Prices. Energy Economics, $31,550-558$.

Kaufmann, T. D. and Winters, R. A. (1989). The Price of Gold: A Simple Model. Resources Policy, 15, 309-313.

Kilian, L. (2009). Not All Oil Price Shocks Are Alike: Disentangling Demand and Supply Shocks in the Crude Oil Market. American Economic Review, 99, 10531069.

Kilian, L. and Lewis, L. (2011). Does the Fed Respond to Oil Price Shocks? Manuscript. University of Michigan.

Kilian, L. and Murphy, D. (2010). The Role of Inventories and Speculative Trading in the Global Market for Crude Oil. CEPR Discussion Paper 7753.

Kilian, L. and Park, C. (2009). The Impact of Oil Price Shocks on the U.S. Stock Market. International Economic Review, 50, 1267-1287. 
Kilian, L. and Vigfusson, R. J. (2009). Are the Responses of the U.S. Economy Asymmetric in Energy Price Increases and Decreases? Manuscript. University of Michigan.

Lee, K. and Ni, S. (2002). On the Dynamic Effects of Oil Price Shocks: A Study Using Industry Level Data. Journal of Monetary Economics, 49, 823-852.

Lee, K., Ni, S., and Ratti, R. A. (1995). Oil Shocks and the Macroeconomy: The Role of Price Variability. The Energy Journal, 16, 39-56.

Lombardi, M. J. and van Robays, I. (2011). Do Financial Investors Destabilize the Oil Price? European Central Bank Working Paper Series No. 1346.

Lütkepohl, H. (2007). New Introduction to Multiple Time Series Analysis. Springer.

Miller, J. I. and Ni, S. (2010). Long-Term Oil Price Forecasts: A New Perspective on Oil and the Macroeconomy. Manuscript. University of Missouri.

Miller, J. I. and Ni, S. (2011). Long-Term Oil Price Forecasts: A New Perspective on Oil and the Macroeconomy. Macroeconomic Dynamics, 15(S3), 396-415.

Miller, J. I. and Ratti, R. A. (2009). Crude Oil and Stock Markets: Stability, Instability, and Bubbles. Energy Economics, 31, 559-568.

Mork, K. A. (1989). Oil and the Macroeconomy When Prices Go Up and Down: An Extension of Hamilton's Results'. The Journal of Political Economy, 97, 740-744.

Narayan, P. K., Narayan, S., and Zheng, X. (2010). Gold and Oil Futures Markets: Are Markets Efficient? Applied Energy, 87, 3299-3303.

Pindyck, R. S. (1994). Inventories and the Short-Run Dynamics of Commodity Prices. The RAND Journal of Economics, 25, 141-159. 
Salant, S. W. and Henderson, D. W. (1978). Market Anticipations of Government Policies and the Price of Gold. Journal of Political Economy, 86, 627-648. 


\section{Appendix 2.A: Figures of Chapter 2}

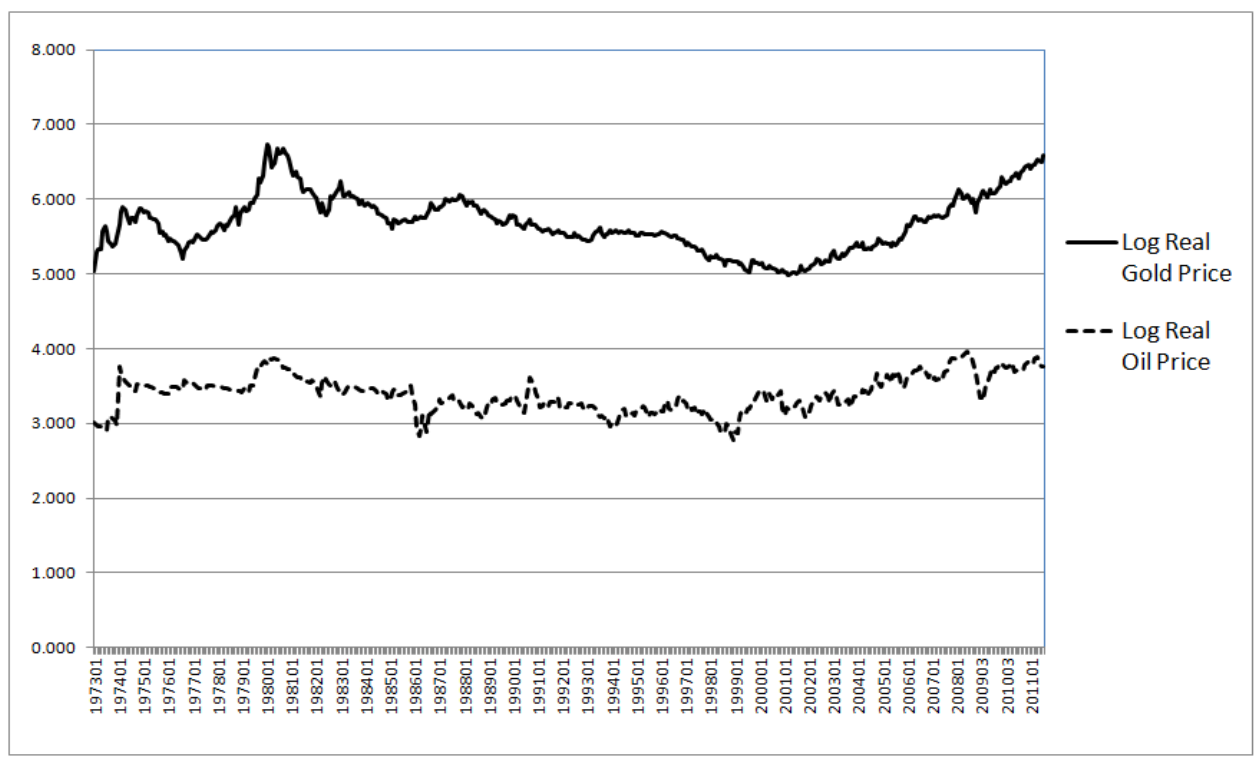

Figure 2.1: Plot of real gold price and real oil price: 1973:1-2011:7; the WTI oil price is deflated by PPI for fuels and related products and power; the gold price is deflated by CPI for all goods; both series are in natural logs. 

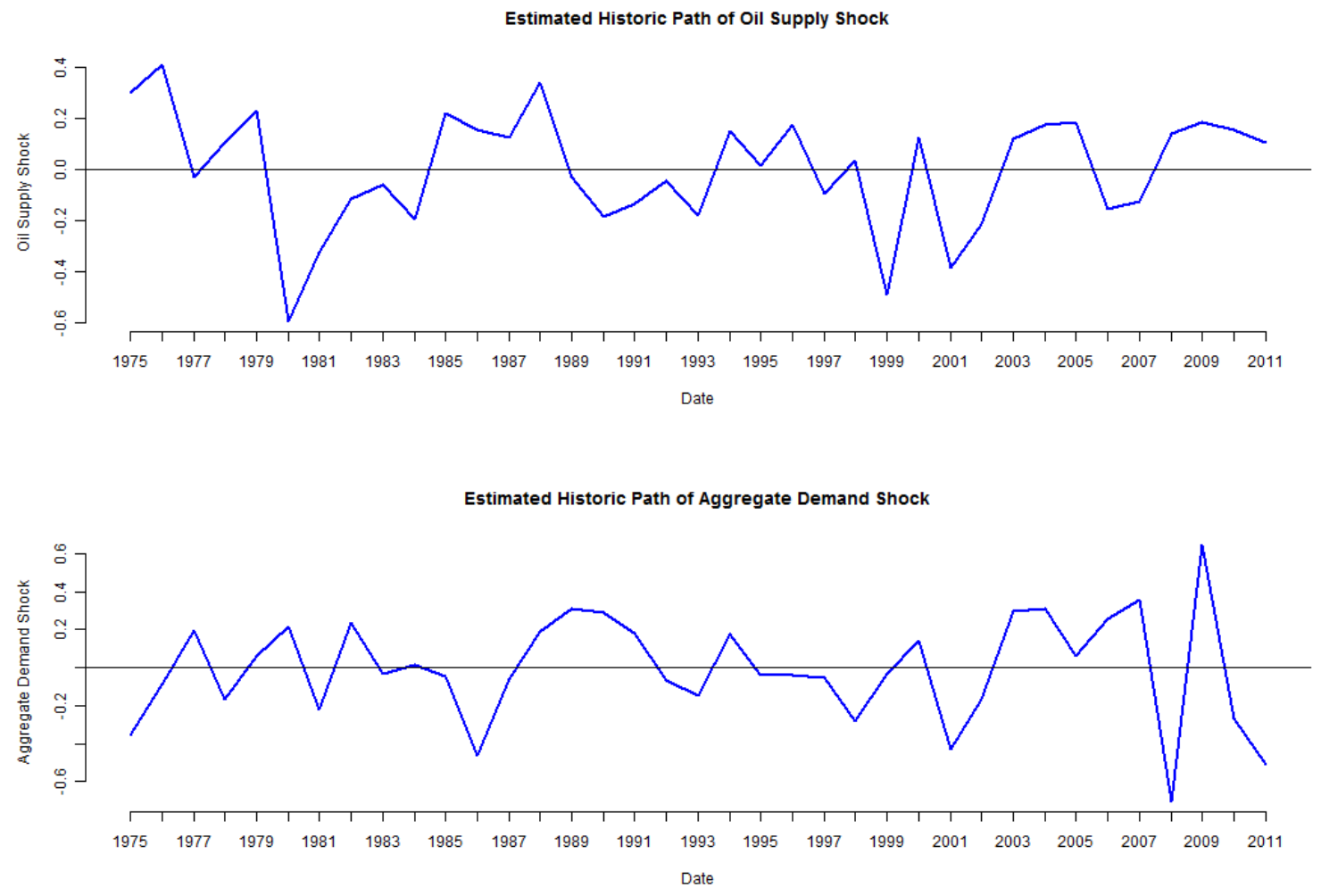

Estimated Historic Path of Speculative Shock

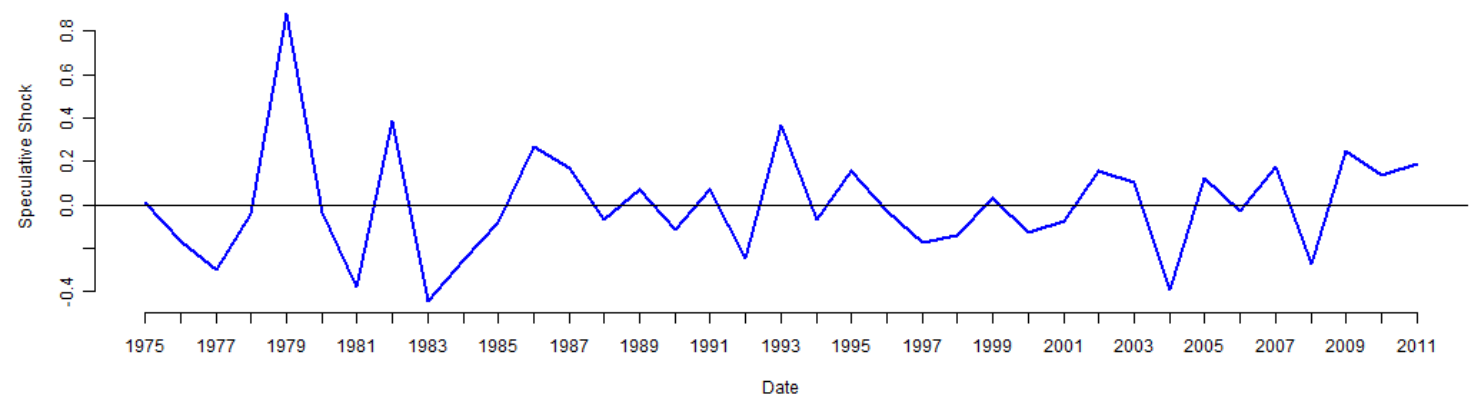

Estimated Historic Path of Residual Shock

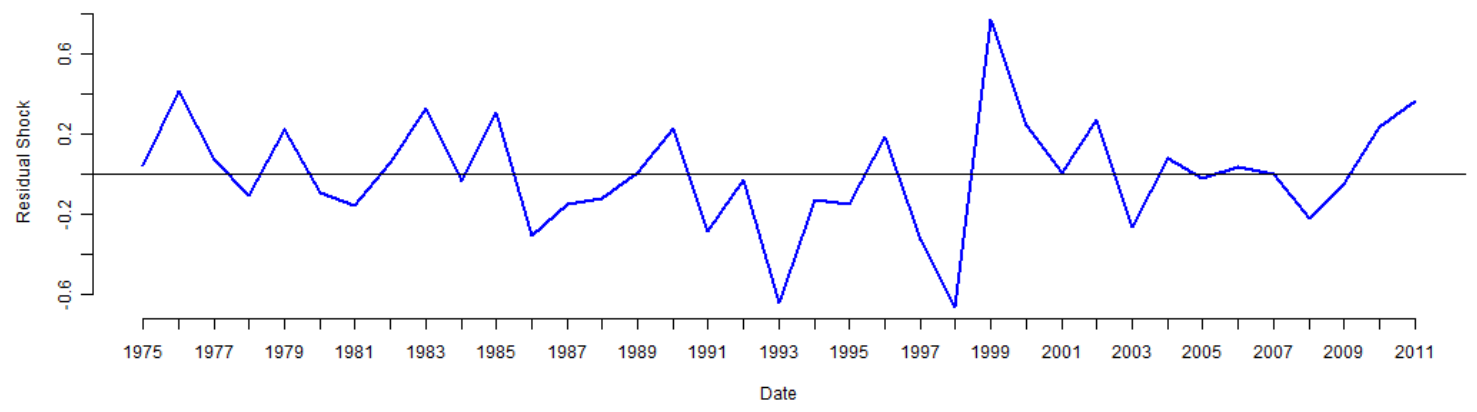

Figure 2.2: Estimated structural shocks from the structural VAR model: values are averaged to annual levels. 

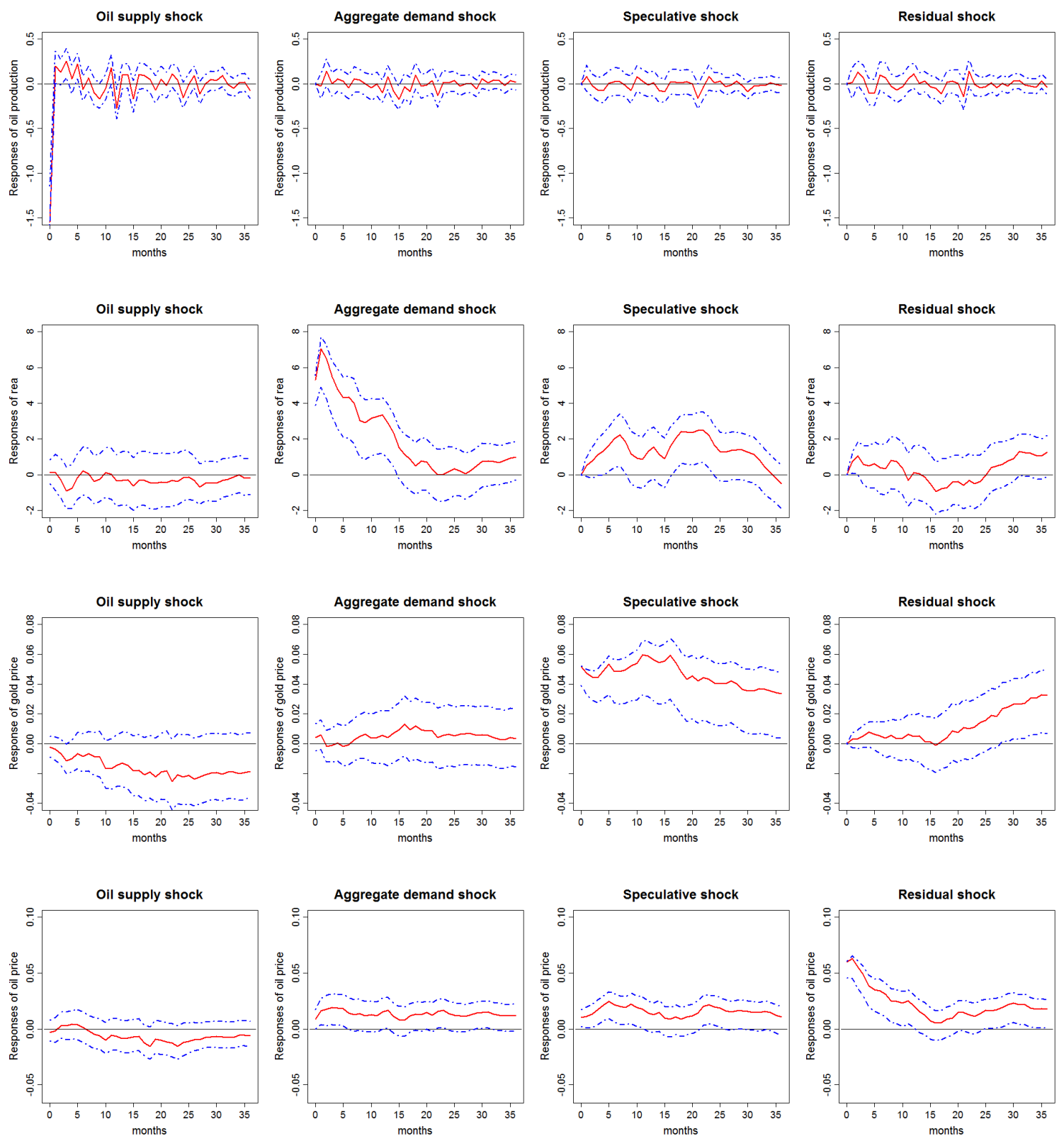

Figure 2.3: Impulse responses of crude oil production, real economic activity, real gold price, and real oil price to each of the orthogonalized structural shocks: $95 \%$ confidence bands constructed based on wild bootstrap of 2000 replications are shown as dashed lines. 

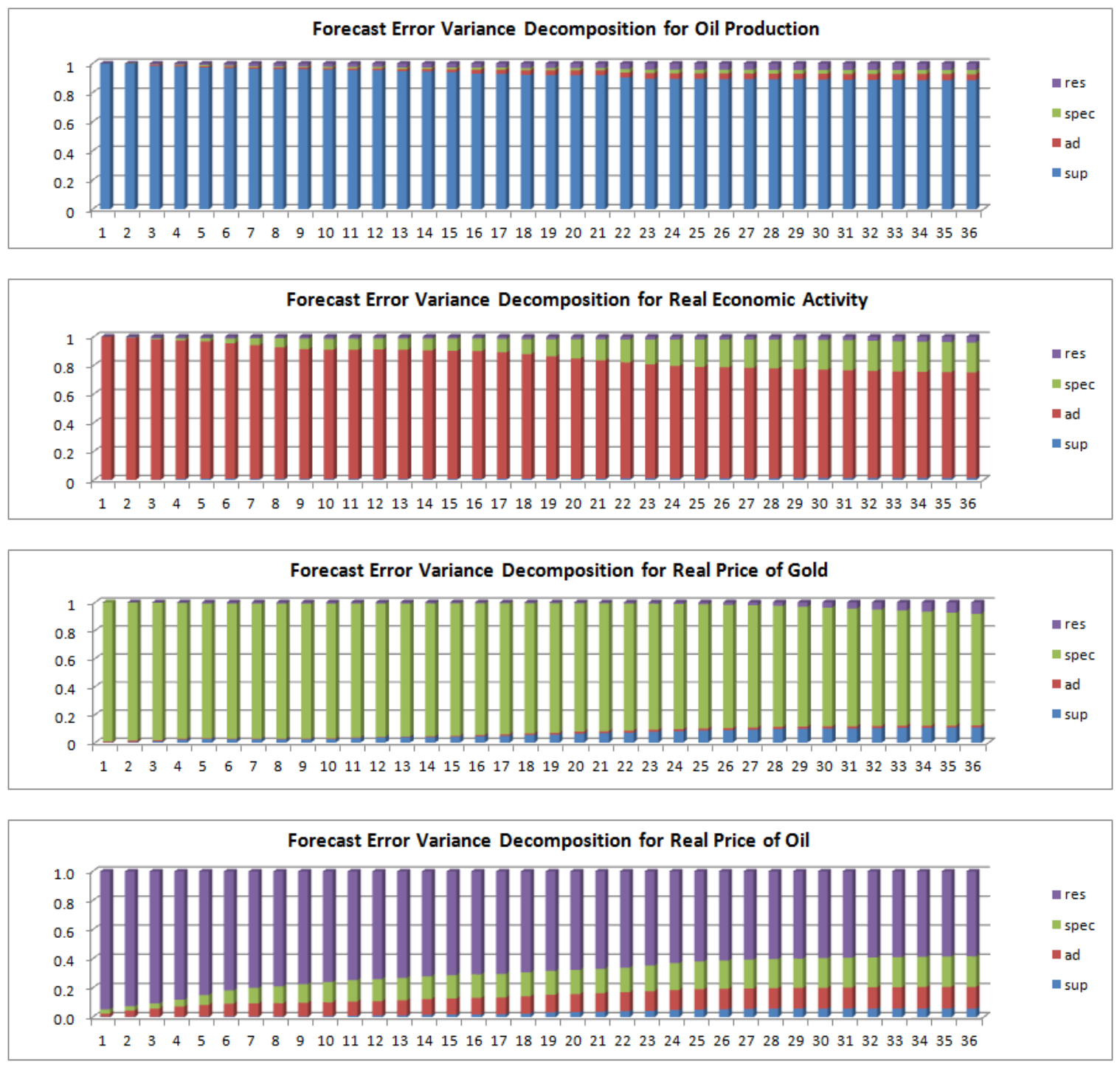

Figure 2.4: Forecast error variance decomposition of oil production, real economic activity, real gold price, and real oil price: sup, oil supply shock; ad, aggregate demand shock; spec, speculative shock; res, residual shock. 

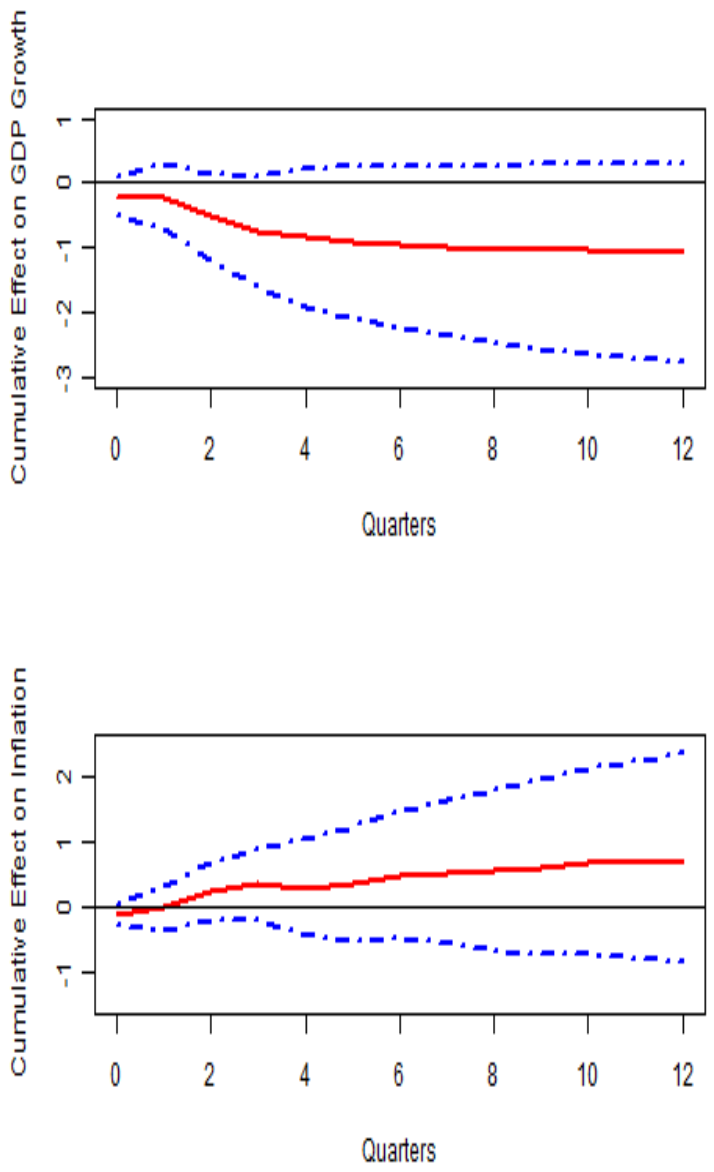

Figure 2.5: Responses of GDP growth and inflation to a speculative shock: levels are shown with the solid line; the $95 \%$ confidence bands based on 10,000 bootstrap replications are displayed by dashed lines. 


\title{
3 Oil Price and the Stock Returns: Volatility Spillovers and Impacts of Oil Price Volatility on Stock Returns
}

\begin{abstract}
In this chapter, we use a generalized autoregressive conditional heteroskedasticity $(\mathrm{GARCH})$ specification to model the volatility on both the oil and stock markets and then utilize an extension of the GARCH-M (GARCH in mean) vector autoregression (VAR) model introduced in Elder (2004) to capture the volatility spillover relationship between the two markets and the relationship between the volatility of the oil price and stock returns at the same time. Further, we detect a structural change of the oil price-stock returns relationship near the middle of 1987. A unidirectional volatility spillover from the stock market to the oil market is found to be statistically significant before the break, while a negative relationship between oil price volatility and the conditional mean of stock returns is more pronounced afterwards. We argue that several events happening around the break point are likely to be the causes for the structural change.
\end{abstract}

Keywords: Oil Price, Real Stock Returns, Volatility Spillovers, GARCH-M JEL Classification Numbers: E44, Q43 


\subsection{Introduction}

The relationship between the oil price and the stock market has been been studied extensively in recent years in addition to the oil price-macroeconomy literature. There are roughly two main streams of the literature in this area. One stream focuses on the relationship between the levels of the oil price and stock returns, and examples include Jones and Kaul (1996), Miller and Ratti (2009), and Kilian and Park (2009). The other stream, however, focuses on the relationship between the volatility of the oil price and stock returns. This group of literature includes Malik and Hammoudeh (2007), which studied the volatility transmission among the oil market and US and Gulf countries stock markets, and Malik and Ewing (2009), which studied the volatility connection between the oil price and stock returns for different sectors. In addition, a few studies also focus on the interaction between oil price volatility and levels of important macroeconomic indicators. For example, Huang et al. (1996) showed that the negative impact from the volatility of the oil futures price is only significant for some individual stocks. Sadorsky (1999) also looked at the volatility of the oil price, and his results only focused on the impact on the macroeconomy.

Recently, several studies contributed to the toolbox for studying the volatility of the oil price. As researchers use conditional variance (or standard deviation) to proxy the volatility of different variables, generalized autoregressive conditional heteroskedasticity $(\mathrm{GARCH})$ models are common in the literature to characterize the evolution of the volatility of the oil price. Based on the GARCH modeling strategy of oil price volatility, there have been modeling techniques aiming to capture the impact of a change of oil price volatility on levels of macroeconomic indicators. One example is the bivariate GARCH-M vector autoregressive (VAR) model introduced by Elder (2004). This model allows a term that represents volatility to directly enter the VAR equations and affect the conditional mean of the autoregressive vector, and thereby 
provides direct evidence on the relationship between the volatility and the conditional mean (or levels). This type of model has been widely used by researchers to study the effect of the oil price volatility and the macroeconomic output, and proved to be useful. ${ }^{1}$ On the other hand, there have not been studies via similar approaches to study the relationship between oil price volatility and the stock markets. As an important economic indicator, stock returns are often referred to, for example, in assessing business cycles and evaluating macroeconomic performances. Therefore, it is important to make additions to our knowledge by studying the effects of oil price volatility on stock markets. Further, it would be useful to develop a model that could capture both the relationship between oil price volatility and levels of stock returns and volatility spillovers between the two markets.

In this chapter, we develop a model that can achieve the above goals. We focus on the volatility spillovers between the two markets as well as the effects of oil price volatility on real stock returns at the same time. Our model is an extension of that in Elder (2004), and we estimate it over the full sample of 1973:1-2011:7, using the data of WTI oil price and the S\&P 500 index returns. Compared to the existing literature, our methodology has several advantages: first, different than Sadorsky (1999), we allow the variations of the oil price to enter the VAR equations to directly affect the conditional mean; second, compared to the literature using GARCH-M models, we allow potential volatility spillovers between the oil and stock markets; third, motivated by an exploratory study using the sample periods found in Miller and Ratti (2009), we use a rolling-window approach to detect a structural break involved in the oil price-stock returns relationship, such that the oil price-stock returns relationship behaves differently before and after the break. In addition, our model also restricts the feedback between the levels of the oil price and the stock market returns to be unidirectional that we only allow the stock returns to react contemporaneously

\footnotetext{
${ }^{1}$ See, for example, Elder and Serletis (2010) and Rahman and Serletis (2011).
} 
to the oil price, but not in the other direction. We are actually not alone in imposing such a restriction on the model, given that there have been studies that argue that it takes time for oil price to respond to changes in stock markets. ${ }^{2}$

While the exploratory estimation indicates that there may be a structural break during the late 1980s, the rolling-window approach finds the most likely break point is between 1987:5 and 1987:6. We observe very distinct observations for the two time periods of 1973:1-1987:5 and 1987:6-2011:7. For the former time period, we observe a significant volatility spillover between the two markets, although the transmission seems to be unidirectional from the stock market to the oil market. Further, an increase in oil price volatility seems to only affect stock returns negatively through the channel of higher oil prices. In contrast, for the latter time period, we find that the volatility spillover relationship disintegrates, implying that the two markets are more disconnected in terms of volatility interactions. However, we see that an increase of oil price volatility has a significant negative impact on stock returns. Based on the empirical results, we argue that the major events dated close to the middle of 1987 are likely the reason why the relationship has changed. The potential causes discussed include the OPEC collapse and the oil glut during late 1985 and the recovery process continued afterwards, the Tax Reform Act of 1986 in the US, which likely depressed the incentives of investors, and the stock market crash in 1987, which likely resulted in better regulations on the stock market and higher information availability.

We organize the rest of the chapter as follows. In Section 3.2, some important literature is reviewed to introduce the background for our study. Section 3.3 discusses the GARCH-M VAR model with some important parameter choices and the data we use for estimation. An exploratory study using presumed structural break points based on Miller and Ratti (2009) is shown in Section 3.4, giving preliminary evidence of a structural break during the late 1980s. Based on that, we use the rolling-window

\footnotetext{
${ }^{2}$ See, for example, Kilian and Park (2009).
} 
approach to detect more accurately the break point, and the results are presented in Section 3.5. Finally, Section 3.6 makes conclusions and comments on potential future research.

\subsection{A Literature Review}

There has been a vast amount of literature studying the relationship between the oil price and the growth of the macroeconomic output in the US. At the same time, there is also a considerable amount of literature discussing the relationship between the oil price and stock markets. Jones and Kaul (1996) tried to justify the reaction of the international stock market to oil price shocks. They studied the postwar data and their findings suggested that the link between the U.S. and Canadian stock markets and the oil price can be completely accounted for by solely the impact of oil price shocks on real cash flows; however, oil price shocks cause larger stock price instabilities than can be attributed to the impact on real cash flows.

Miller and Ratti (2009) studied the long-run relationship between the oil price and the world stock market, and they detected that structural breaks are involved in this relationship. Specifically, using monthly data, they claimed that the time points of the structural breaks are after 1980:5, 1988:1, and 1999:9. They found that the long-run relationship was significant during the first and third time period formed by these dates. However, the relationship is not significant for the period of 1980:6-1988:1, and it "disintegrated" after 1999:9. In addition, Arouri and Rault (2012) studied the long-run relationship between the oil price and the stock market for the GCC (Gulf Cooperation Council) countries. Their approach is based on a panel analysis and seemingly unrelated regression models. Their results suggest that there is generally a positive relationship between the oil price and the stock markets for these countries, with the only exception of Saudi Arabia. 
Zhu et al. (2011) used a panel threshold cointegration approach to study the oil price-stock markets relationship for OECD and non-OECD countries. Their study found that there is a nonlinear cointegration relationship between the oil price and the stock market. Further, they found that, using VECM methods, the long-run relationship between the oil price and stock markets involves bidirectional Granger causality, regardless of OECD or non-OECD countries. They also found that there is a positive impact on the stock prices when there is an increase in the oil price.

Kilian and Park (2009) used an identified structural VAR model to decompose the oil price shocks and they argued that depending on the nature of the driving forces of the oil price shocks, the effects on the stock prices are likely to be different. Particularly, they argued that only those oil price increases that are driven by the "precautionary demand" in fear of limited future oil availability cause stock prices to go down significantly. The oil price increases caused by the global economic expansion, however, cause the stock prices to go up, which helps explain the empirical evidence that stock prices and the oil price are correlated positively during some time when the oil price increases.

Filis et al. (2011) studied the effects of oil price changes on stock markets in oilimporting countries and oil-exporting countries. Their study followed the definition of the oil price shock sources that is similar to Kilian and Park (2009), but with the implementation of a DCC-GARCH-GJR approach. The results suggested, unlike that documented in Kilian and Park (2009), that the oil price has a universal negative impact on the stock markets regardless of the driving forces of oil price shocks. One exception, though, is that during the financial crisis around 2008, oil price changes actually showed positive co-movements with the stock markets. Zhang and Chen (2011) yet used the $\mathrm{ARJI}\left(-h_{t}\right)$-EGARCH model to study the relationship in the context of China's stock markets. By separating the oil price changes into expected, unexpected, and negative unexpected shocks, they found that China's stock markets 
are only related to the expected shocks, and the linkage is weak.

Fayyad and Daly (2011b) also used a VAR model to study the oil price-stock returns relationship for some GCC countries as well as two advanced economies: UK and US. They found that the impacts of oil price changes on the stock returns are different depending upon when the oil price shocks happened: the impacts are stronger after an oil price increase and during the global financial crisis, while weaker during other times. It is also shown that the oil price-stock returns relationship is different across countries. Their results show that the stock returns in Qatar and the UAE are more responsive to an oil price shock than the rest of GCC countries, while UK is more responsive than the US in the developed countries.

Filis (2010) used cointegration and a VECM, as well as a VAR model, to show that the oil price has a significant negative impact on the stock market in Greece. The author also argued that the study provides important information to policy makers. Jammazi and Aloui (2010) take another approach. The authors utilized both the wavelet analysis and Markov Switching VAR model to study the oil price changes and the stock returns in three countries: UK, France, and Japan. The study found evidence that oil price shocks do not affect the stock market during the recession, but significantly reduce the stock market expansion phases. Further, their results showed that the long-run relationship between the oil price and stock markets seems to only exist before 1999, echoing the results of Miller and Ratti (2009).

In contrast to many studies, Kapusuzoglu (2011) investigated the long-term and short-term relationships between three stock indices in Turkey and the oil price for the 10 years after April 2000. It is shown that each of the indices is cointegrated with the oil price based on Johansen test. However, the direction of the Granger causality was from stock market to the oil price, rather than from the oil price to stock market, as shown in much of the literature. Kapusuzoglu and Karan (2011) conducted similar research on 24 OECD countries and showed similar results for the cointegration rela- 
tionship between the oil price and stock markets. However, they showed that among the oil price and the stock prices there are extensive multi-directional relationships and suggested that the oil price-stock markets relationship varies across countries, depending upon the country-specific factors, such as oil dependency.

Conrad et al. (2012) used a modified version of the DCC-MIDAS model to find the oil price-stock market relationship to be countercyclical: the relationship is negative during economic expansions and positive during economic recessions and recoveries. In addition, the paper also studied the relationship between the economic performance and the long-term volatilities of the oil price and stock returns. They argued that the volatilities on the oil market as well as the stock market are subject to the impact of the same macroeconomic factors.

The volatility of oil price is the subject of a large amount of the literature, among which many studies focus on the impacts of the volatility of the oil price on the macroeconomy. Lee et al. (1995) used a VAR model, where the errors are modeled by a GARCH process, to study the effects of oil price volatility on the macroeconomy. Their results implied that the volatility of the oil price matters to the fluctuations of the macroeconomic performance. Their methodology, however, has been criticized because of the nature of a two-step regression with generated regressors.

There are also some studies that aim to explain the empirically documented asymmetry associated with the oil price-macroeconomy relationship. The rationale is that both oil price increases and decreases cause uncertainty on the oil price and therefore depress the incentives of investment activities. Among many, Federer (1996) accounts for the documented asymmetry of the oil price-macroeconomy relationship by oil price volatilities caused by the changes in levels of the oil price. The results show that the oil price volatility is a bigger player in suppressing the economic growth than the oil price level changes. In addition, Hooker (1996) finds that for more than 20 years after 1973:4 (April 1973), changes of the oil price were less important compared to 
the oil price volatilities in predicting the aggregate output movement. Moreover, for 1984-2004, Guo and Kliesen (2005) used a measure of volatility based on oil futures prices and showed that an increase in oil price volatility will significantly cause a decline in economic growth.

There are also several studies exploring the volatility spillovers between the oil market and the stock market. For example, Fayyad and Daly (2011a) modeled the two markets using the BEKK-GARCH model for the GCC countries as well as UK and the US. Their results suggests that there are strong bidirectional volatility spillover effects between the oil market and the US stock market, but it is not true for the other countries considered in the paper. In particular, the stock market in UK is not subject to the volatility spillover from the oil market, but the oil market is subject to the volatility spillover from the stock market in UK. Another paper by Jammazi (2012) studied the volatility spillover from the oil market to the stock markets in five developed economies including US. The BEKK-Markov Switch GARCH model was used to allow flexibilities of reactions between means and volatilities of the two markets, and both WTI and Brent oil prices are used for comparison. For the US, it is shown that an increase of the WTI oil price volatility may cause a higher stock market volatility, but for the Brent oil price, the relationship is inverse. It is also shown that the impact on US stock market from oil price shocks are very minimal in that stock market crash is not likely to be caused by oil price shocks.

In addition, Malik and Hammoudeh (2007) studied the volatility transmission among the oil market and US and Gulf countries stock markets. Their results show that for most Gulf countries, the stock market volatility is affected by oil price volatility. In the case of the US, they found that the volatility spillovers between the oil market and the stock markets are significant. On a disaggregated level, Malik and Ewing (2009) studied volatility spillovers between the oil market and the sectoral stock returns using weekly data from 1992:1 to 2008:4. They found that there are 
volatility spillovers between the oil market and each of the five sectoral stock returns: the financials, the technology, the consumer services, the health care, and the industrials. Nonetheless, the oil price-stock returns volatility spillover mechanism varies for different sectors.

There are also a few studies examining both the level effects and volatility effects. Huang et al. (1996) studied the relationship between oil futures returns and stock returns based on daily data largely from the 1980s. Their results suggest a justifiable relationship during this time span only between the oil futures returns and oil-related stock returns, but not between the oil futures returns and the general stock market returns. They also studied the lead-lag relationship between oil price volatility and stock returns volatility, and showed that the volatility of oil futures returns leads the oil-related stock index volatility. However, the oil volatility studied in this paper is associated with oil futures returns rather than with the spot oil price itself. While it is helpful to understand how the stock and oil futures markets are linked, it is also important to understand the relationship between the stock market and the spot oil price and its variations.

Sadorsky (1999) studied the relationship between the oil price and the stock market. He used a $\operatorname{GARCH}(1,1)$ specification to model the volatility of the oil price and his results suggested that, in addition to oil price changes, the volatility of the oil price is also responsible for variations of real stock returns. However, his model did not allow the volatility to directly affect the conditional mean or stock returns.

A useful toolbox that allows us to directly examine the impact of volatility on conditional means is the GARCH-M models. There is a battery of studies featuring GARCH-M VAR models in studying the impact of oil price volatility and the macroeconomy. Among these, Elder and Serletis (2010) studied the impact of oil price volatility on the GDP using a GARCH-M VAR model introduced in Elder (2004). They captured the volatility via the means of the standard deviation of conditional 
forecast error, which is modeled by a $\operatorname{GARCH}(1,1)$ process. The problems with the methodology in Lee et al. (1995) are overcome by estimating the whole system using the maximum likelihood approach in their study. The authors argued that the introduction of the volatility terms into the VAR model significantly improved the fit of the model, and showed that the GDP is significantly affected negatively by the forecasted volatility of the oil price. In addition, their study also showed significant negative effects of oil price volatility on some of the subsets of the GDP, e.g. durable goods consumption and most private investment sectors.

Rahman and Serletis (2011), on the other hand, studied the asymmetric effects of the oil price shocks on output growth by applying a different GARCH-M VAR model. They used a modified BEKK model that allows for spillovers between variances to characterize the evolution of the volatility of the output growth and the oil price. In addition, their GARCH process included a term accounting for the asymmetry on the effects of recent forecast errors. It was found that oil price volatility is negatively correlated to the output growth and the effects of innovations to the price of oil as well as that to its volatility are asymmetric.

In this chapter, we use an extension of the model found in Elder (2004) to focus on both the volatility spillover between the oil and stock markets, as well as the impact on stock returns from oil price volatility. Starting from the next section, we present the model, the empirical results as well as the discussions about the empirical evidence. 


\subsection{The Model and Data}

\subsubsection{The GARCH-M VAR Model}

The evidence of conditional heteroskedasticity of oil price changes and stock returns are well documented in several papers. ${ }^{3}$ For our purpose of allowing the volatility of the oil price to directly affect the conditional mean, we propose a GARCH-M VAR model to capture the joint movement of the oil price and the real stock returns. Specifically, we assume that both the oil price change and the stock market returns at a particular time can each be expressed as a linear combination of the lags of both variables plus terms representing the conditional standard deviations for both variables. The GARCH-M VAR model can thus be written as follows:

$$
A y_{t}=B_{0}+\sum_{i=1}^{p} B_{i} y_{t-i}+\Phi \operatorname{diag}\left(H_{t}\right)^{1 / 2}+\epsilon_{t}
$$

where $y_{t}=\left[\Delta \ln p_{t}, r_{t}\right]^{\prime}$, is a $2 \times 1$ vector containing the variables of interest. Here $\Delta$ is the operator of first time difference, $p_{t}$ is the real oil price at time $t$, and $r_{t}$ is the stock return at time $t$, which is calculated by the first difference of the logged stock indices. In order to obtain real stock returns, the stock indices are deflated by consumer price index $(\mathrm{CPI})$. The operator $\operatorname{diag}(\cdot)$ extracts the diagonal elements of a matrix to form a vector. We assume that $\epsilon_{t} \mid \Omega_{t-1} \sim$ i.i.d. $N\left(0, H_{t}\right)$, where $\Omega_{t-1}$ is the information set at the end of time $t-1$. The matrix $A$ is a $2 \times 2$, lower triangular matrix characterizing the structural relationship between the structural innovations, which is a similar specification found in several studies. Specifically, by this lower-triangular specification of $A$ we enforce the restriction that only stock returns respond to oil price shocks within the same period, while the oil price responds to the stock market innovations not during the same period, but with a delay. In addition, the diagonal

\footnotetext{
${ }^{3}$ See, for example, Sadorsky (1999) and Akgiray (1989).
} 
elements of $A$ are normalized to unity so that we only need to estimate one parameter, i.e. $A(2,1)$, for this matrix. Matrices $B_{i}$ 's $(i=0, \cdots, p)$ are the coefficient matrices for the AR part of the equation, each of which has the same dimension as that of the matrix $A$. $\Phi$ is the coefficient matrix for the conditional standard deviation terms, which contains the square roots of the diagonal elements of the matrix $H_{t}$, by which oil price volatility and real stock returns volatility are measured. Therefore, examining the effects of oil price volatility on real stock returns, holding the oil price constant, becomes as straightforward as testing the hypothesis that the relevant component contained in $\Phi$ is zero (i.e. $\Phi(2,1)=0)$.

The univariate ARCH and GARCH modeling strategies were introduced by Engle (1982) and Bollerslev (1986), and then have been widely applied to solve a large range of empirical problems. In order to model the heteroskedasticity involved in the joint movement of the oil price and the stock returns, we use a bivariate $\operatorname{GARCH}(m, k)$ specification, following what was introduced in Engle and Kroner (1995). Hence, assuming the distribution of the error terms in Equation (3.1) are jointly Gaussian, the variance-covariance matrix $H_{t}$ can be modeled as follows:

$$
\begin{aligned}
\operatorname{vec}\left(H_{t}\right) & =C^{*}+\sum_{i=1}^{m} D_{i}^{*} \operatorname{vec}\left(\epsilon_{t-i} \epsilon_{t-i}^{\prime}\right)+\sum_{j=1}^{k} E_{j}^{*} \operatorname{vec}\left(H_{t-j}\right), \\
\epsilon_{t} & =H_{t}^{1 / 2} z_{t} \\
z_{t} & \sim \text { i.i.d. } N(0, I)
\end{aligned}
$$

where $\operatorname{vec}(\cdot)$ is the operator that stacks all the columns of a matrix together to form a vector. As argued in Elder and Serletis (2010), the estimation of this equation is computationally expensive, even when $m=k=1$. Elder (2004) used additional assumptions based on the usual VAR identifying assumptions that the errors are contemporaneously uncorrelated, so that the number of parameters that need to be estimated are further reduced. Specifically, with the assumption that there is no 
contemporaneous correlation between the innovations of oil price change and real stock returns, the conditional covariance terms contained in $H_{t}$, or the off-diagonal elements of $H_{t}$, are zeros. Following this assumption, we can show that the GARCH model can be written as follows:

$$
\operatorname{diag}\left(H_{t}\right)=\widetilde{C}+\sum_{i=1}^{m} \widetilde{D}_{i} \operatorname{diag}\left(\epsilon_{t-i} \epsilon_{t-i}^{\prime}\right)+\sum_{j=1}^{k} \widetilde{E}_{j} \operatorname{diag}\left(H_{t-j}\right)
$$

where the operator $\operatorname{diag}(\cdot)$ trimmed the zero off-diagonal elements. It should be noted that in this equation, $\widetilde{C}, \widetilde{D}_{i}$ 's $(i=1, \cdots, m)$, and $\widetilde{E}_{j}$ 's $(j=1, \cdots, k)$ all have different dimensions than that of $C_{i}^{*}, D_{i}^{*}$ s and $E_{j}^{*}$ s, respectively, in Equation (3.2). Specifically, $\widetilde{C}$ is a $2 \times 1$ vector, and $\widetilde{D}_{i}$ 's and $\widetilde{E}_{j}$ 's are each a $2 \times 2$ square matrix. ${ }^{4}$

Elder (2004) further imposed the restriction that both $\widetilde{D}_{i}$ 's and $\widetilde{E}_{j}$ 's are diagonal as well, assuming that the variance of one variable only depends on its own past errors (or "news") and variances. Please note that our model assumes a more general case than that of Elder (2004), in that we do not particularly enforce the restriction of being diagonal on either $\widetilde{D}_{i}$ 's or $\widetilde{E}_{j}$ 's. Hence, our model presents a more general setup in the sense that it allows spillovers between the "news" and variances, i.e. it allows for the squared error and conditional variance of one variable in the previous time periods to affect the current variance of the other variable. In other words, volatility spillovers are possible in our model. To detect whether or not there is a significant volatility spillover between the two markets, LR tests can be applied to compare the the models with diagonal and non-diagonal $\widetilde{D}_{i}$ 's and $\widetilde{E}_{j}$ 's. For convenience, we call the model with diagonal restrictions on parameter matrices the "no-spillover" model, and the one without such restrictions the "spillover" model. Following the prevailing literature, and also keeping our model parsimonious, we choose $m=k=1$

\footnotetext{
${ }^{4}$ It can be shown that, under the assumption that the innovations are contemporaneously uncorrelated, Equation (3.5) can be derived from Equation (3.2). The detailed derivation is provided in Appendix 3.A.
} 
in Equation (3.5), so that the joint variances follow a $\operatorname{GARCH}(1,1)$ process.

Another parameter we need to select before estimating the model is the lag order for the AR part in Equation (3.1), i.e. the value of $p$. In the literature, the lag order is usually determined in several different ways. For example, Rahman and Serletis (2011) used Akaike Information Criterion (AIC) and Schwartz Information Criterion (SIC) to decide on the lag order and they chose to include 3 quarters of lags in their model. Other people avoid using the information criteria and simply include enough lags for one or two years in model to account for enough seasonality, which is believed to be present with oil price fluctuations. In this study, we choose to follow the latter to include enough lags for a year to account for enough seasonality. Given that our data are monthly, the lag order of $p=12$ is chosen. It is true that the usage of information criteria usually results in smaller lag orders than enough for a year and researchers can argue that their model specification decided by the AIC or SIC are reasonably parsimonious. However, larger lag orders are always more inclusive, especially when it is believed that seasonality is likely to be existent.

\subsubsection{The Data}

The data are obtained from the Federal Reserve Economic Data (FRED) hosted by the Federal Reserve Bank of St. Louis. For the oil price, the monthly West Texas Intermediate (WTI) nominal oil price series are used and we convert the prices into real terms using the producer price index (PPI) for fuels and related products and power. ${ }^{5}$ As noted earlier, we use log-differenced real oil price to capture the oil price changes. For stock market returns, we compute monthly market returns using the S\&P 500 index as follows. We first obtain the S\&P 500 index series, which are

\footnotetext{
${ }^{5}$ There are other studies that use consumer price index (CPI) to deflate the oil price, but we choose to use PPI because we believe that the oil price affects the economy largely because crude oil is used as an input for producing other goods. There exist many other papers that use PPI to deflate the oil price, for example, Miller and Ni (2011) used PPI for all commodities to deflate the nominal oil price series.
} 
available at daily frequency, from FRED as well. ${ }^{6}$ Then we use the index values at the end of each month to construct monthly data. To calculate monthly real returns from the stock market, we first use CPI for all commodities to deflate the monthly indices and then take log-differences of the deflated indices to calculate monthly stock market returns. The data pool is from January 1973 to July 2011.

Figure 3.1 shows the historical path of the real oil price. The real oil prices are in natural logs. In earlier years, the oil price experienced large surges during the 1973/4 period, early-1980s, and early-1990s. These oil price surges are well-known for their causes. For example, the early-1990s oil price surge was caused by the first Gulf War. In contrast, the oil price plunged during 1985/86 and late-1990s. After the late-1990s plunge, the oil price gradually increased, recovering from the plunge and reached the highest point of the sample around 2008. There was a brief decrease from late-2008 to early-2009, but the oil price recovered soon and stayed at relatively high levels since then.

Figure 3.2 shows the history of stock market returns, which are calculated based on the deflated S\&P 500 index series. As one might expect, the stock market return fluctuates continually. The plot also shows that stock returns generally stayed within the range between positive $5 \%$ and negative $5 \%$, which we call "average range". The number of observed stock returns that are within the "average range" are 355, or about $77 \%$ of the sample. Despite the constant fluctuation, however, we can still observe some facts about the movement of stock returns. First, stock returns were generally negative during the 1973-74 period, and this time was when the oil price spiked. Stock returns then quickly hit high around 1975 and experienced large fluctuations yet stayed mostly positive until 1976, when it started to move back and forth between positive and negative values within the "average range". Second, negative stock re-

\footnotetext{
${ }^{6}$ The S\&P 500 index includes only those relatively larger firms. However, it may be the case that smaller firms behave differently than the larger ones in response to oil price fluctuations. For this chapter, we only consider the larger ones, and studies on smaller firms can be conducted using different stock indices.
} 
turns dominated during period of late-1970s to early-1980s. This is the time when oil price surged. Then the positive stock returns dominated between 1981 and 1985, when the oil price was gradually decreasing. Stock returns had large fluctuations during 1986-1988, around the historical stock market collapse. This collapse seemed to happen just in line with the wide fluctuation of the oil price around similar time. Third, stock returns were largely within the "average range" during most time in the 1990s, but there was a large collapse around the 1998-1999 period. This is when the oil price collapsed as well. Fourth, stock returns were fluctuating in a large range but were generally negative in 2000-03, but the oil price was relatively stable during this time frame. Lastly, the stock market collapsed and thus stock returns were staying largely negative during the 2008-2009 financial crisis, and this corresponds to a large fluctuation of the oil price.

Several observations noted above are particularly interesting, since they present evidence that is in contrast with the findings in several existing papers, which claim the relationship between the oil price and stock returns to be negative. Based on the negative oil price-stock return relationship, however, one could not explain the simultaneous collapse of the oil price and stock returns during 1998-1999. Neither could one explain the bad stock returns during 2000-2003, or why stock returns did not move oppositely while the oil price spiked and then plunged in 2008-2009. On the other hand, if the hypothesis is valid that large oil price volatility, or the uncertainty that is related to oil price variations, has a negative impact of stock returns because of the delay of action it causes for investors, then these "odd" observations about the movements of the oil price and stock returns could be explained. For 1998-1999, the collapse of oil price increased uncertainty about the oil price, and around similar time, stock returns experienced a big plunge. For 2000-2003, the volatility of the oil price was also considerable, while the stock returns stayed generally negative for that time. Finally, the wide range of oil price fluctuation during 2008-2009 also corresponds to 
negative stock returns.

Before we formally estimate the model, however, we need to be concerned about the structural breaks that might be associated with the oil price-stock relationship. There have been several papers mentioned in the literature review section that suggest potential changes (or instability) of the oil price-stock relationship, and therefore structural break is highly possible for the sample period we study. In order to avoid missing the potential structural breaks, we first conduct exploratory estimation of our model based on the structural breaks identified by Miller and Ratti (2009), and then estimate our model using the rolling-window technique to determine the most likely break point.

\subsection{Exploratory Estimation Based on Presumed Break Points}

Miller and Ratti (2009) documented significant structural breaks for the longrun relationship between the oil price and the stock market. They found that the relationship is not stable and the structural breaks detected are after 1980:5, after 1988:1, and after 1999:9. Motivated by these structural shocks and as an initial step to find evidence of structural breaks, we fit our model over the whole sample period, 1973:1-2011:7, as well as over three subsamples, 1973:1-1988:1, 1988:2-1999:9, and 1999:10-2011:7. We choose not to use the structural break identified after 1980:5 to form an additional subsample, and the reasons are as the following. First, using the 1980:5 structural break would split the subsample 1973:1-1988:1 into two subsamples that are much smaller. As will be shown later, the number of parameters to be estimated is very large, so the small samples will suffer the problem of too few degrees of freedom. Second, we also want the sizes of the subsamples to be relatively comparable. Dividing the subsample of 1973:1-1988:1 would make the resulted 
two subsamples significantly smaller than 1988:2-1999:9 and 1999:10-2011:7. Therefore, as an exploratory step, we choose to construct the three subsamples for initial investigation.

\subsubsection{The MLE estimation and the LR test of volatility spillover}

To estimate our model given by Equations (3.1) and (3.5), we use the maximum likelihood method. The key advantage of the maximum likelihood method is that it allows us to estimate all parameters within one step. This way, we avoid the potential issues associated with generated regressors and problematic test statistics. Assuming the errors are Gaussian, the objective log-likelihood function we maximize can be written as

$$
\mathcal{L}=\sum_{t=1}^{T}\left[\ln |A|^{2}-\ln \left|H_{t}\right|-\epsilon_{t}^{\prime} H_{t}^{-1} \epsilon_{t}\right],
$$

where additive and multiplicative constants are pared appropriately so that the maximization outcome will not be affected. The initial value of the series $H_{t}, H_{0}$, is determined based on the pre-sample values of the data, i.e. from $y_{-p+1}=y_{-11}$ to $y_{0}$, if we denote the first observation in our effective sample as $y_{1}$. Additionally, as we mentioned earlier, we estimate our model with two versions of Equation (3.5) and use the LR test to determine if the no-spillover model is adequate in capturing the relationship. In particular, for each sample, we use likelihood ratio test to determine whether the estimation is significantly improved by removing the diagonal restrictions

on the matrices $\widetilde{D}_{1}$ and $\widetilde{E}_{1}$. If the estimation is significantly better when we remove the restrictions, then there is evidence that the no-spillover specification should be dropped and the spillover specification needs to be adopted. However, if the relaxed model fits only marginally better than the restricted one, we can then conclude that the evidence is not strong enough to overturn the no-spillover assumption, and the 
no-spillover specification is adequate to capture the relationship we are interested in. Following the rules of the likelihood ratio test, our test will be based on the $\chi^{2}(4)$ distribution. We use this method for the whole sample and each of the subsamples as well.

Given the lag order in our model, $p=12$, the total number of parameters that need to be estimated for the no-spillover specification is $4 \times 12+13=61$. For the alternative specification that allows spillover effects, the number of parameters to be estimated will be 65 , as the off-diagonal elements of $\widetilde{D}_{1}$ and $\widetilde{E}_{1}$ will need to be estimated as well.

In the following subsections, we first present the results of estimation for the whole sample of 1973:1-2011:7. After that, we present the estimation results for the subsamples in the time order.

\subsubsection{Estimation over the whole sample: 1973:1-2011:7}

Table 3.1 shows the coefficient estimates for Equation (3.5) for both the spillover and no-spillover specifications. We can see that the GARCH coefficient estimates for the no-spillover and spillover specifications are not very similar. In particular, the coefficient estimate on $\epsilon_{s r, t-1}^{2}$ in the oil price equation after we remove the nospillover restrictions is considerably different than zero. In addition, the coefficient estimate on $H_{o p, t-1}$ has decreased after removing the restrictions. However, despite of these differences, the rest of the coefficient estimates are very similar between the two specifications.

Table 3.2 shows the point estimates of the impact of the oil price volatility on the real stock returns holding the oil price changes constant, namely, $\Phi(2,1)$, for the alternative specifications of our model. The left side t-test $p$-values for these point estimates are presented in parentheses. We report one-sided $p$-values because our primary purpose of the t-tests about $\Phi(2,1)$ is to find evidence for the parameter to 
be significantly negative. For the purpose of conducting the likelihood ratio test, the $\log$ likelihood value for each specification and the likelihood ratio test statistic are also reported. As we see in the table, however, the coefficient estimates on $\Phi(2,1)$ for both specification are very close to zero, and have opposite signs (-0.044 vs. 0.009). In addition, the $p$-values ( 0.22 vs. 0.57$)$ also suggest that neither of the estimates from the two specifications of our model is statistically significant at any reasonable Type I error rate. In addition, the LR test implies that, despite the difference we observe in the coefficient estimates in Table 3.1, we cannot reject the no-spillover specification at $5 \%$. However, regardless of the model selection, we do not observe a strong negative impact from oil price volatility on stock returns. Further, the failure to reject the no-spillover specification indicates that there is no significant volatility spillover relationship between the two markets.

\subsubsection{Estimation over the subsamples: 1973:1-1988:1, 1988:2- 1999:9, and 1999:10-2011:7}

In this section, we estimate our model over the three subsamples formed by the presumed structural breaks discussed above.

The first subsample is from 1973:1 to 1988:1. The estimated coefficients for Equation (3.5) are shown in Table 3.3. We can observe several differences for the coefficient estimates. The constant term in the oil price equation decreases from 7.36 to 0.01 when we remove the restrictions of no-spillover effects. Also changed significantly is the coefficient estimate for $H_{o p, t-1}$, which increases from 0.37 to 0.52 . The coefficient estimate on $\epsilon_{s r, t-1}^{2}$ also increases to 0.09 from the restricted 0. However, the coefficient estimates for the equation of real stock returns variance did not change very much. The coefficient estimates that are zeros in the no-spillover model become slightly negative, but the magnitudes of these estimates indicate that these estimates do not affect the economic meaning of the model very much. Table 3.4 shows the 
estimates for $\Phi(2,1)$ with the log likelihood values and the likelihood ratio test statistic. The estimates of $\Phi(2,1)$ are somewhat different for the two specifications. For the no-spillover model, the estimate is -0.057 and for the spillover model, it is -0.044 . However, the left side $p$-values are very similar (0.22 vs. 0.23$)$ and they suggest that neither estimate is statistically significant at any reasonable Type I error rate. We do have the log likelihood values (-1050.530 vs. -1045.240) and the likelihood ratio test statistic (10.580) indicating that we need to reject the no-spillover specification in favor of the spillover one. To summarize, the study on this subsample suggests that there is volatility (or variance) spillover between the oil market and the stock market, but high oil price volatility does not seem to be correlated with negative stock returns, assuming that the oil price stays the same.

Table 3.5 shows the estimated coefficients for Equation (3.5) over the subsample 1988:2-1999:9. Comparing the GARCH coefficient estimates for the two specifications, we observe very little difference other than several coefficient estimates that are restricted to be zeros in the no-spillover model become slightly negative in the no-spillover model. This implies that the specification restricting the spillover effects is likely to be adequate for characterizing the GARCH process for this time period. Table 3.6 shows the estimates of $\Phi(2,1)$ with corresponding one-sided t-test $p$-value in parentheses. We can see that the two specifications result in identical estimate for $\Phi(2,1)$, and the only difference lies in the $p$-values, indicating that the estimate under the spillover specification is more statistically significant, although both estimates are significant at any reasonable Type I error rate. The log likelihoods are very similar for the two specifications, yielding a LR test statistic of 1.990, so we can conclude at any reasonable significance level that the no-spillover model specification is adequate in accounting for the GARCH process in our question. To summarize, for this time period, the volatility spillover effect between the two markets vanishes, but an increase in oil price volatility has a significant negative impact on stock returns, 
holding the oil price constant. Furthermore, in light of the study by Miller and Ratti (2009), it seems that the relationship between the oil price and stock markets is two folds during this time period. First, as documented by Miller and Ratti (2009), the long-run relationship between the oil price and stock markets is significant. Second, as our results suggest here, there is another piece of impact on the stock markets that comes from the oil price fluctuations through volatility. Hence, for this time period, both changes in oil price levels and volatility are important to the stock market.

The last subsample is 1999:10-2011:7, during which time Miller and Ratti (2009) did not find significant long-term relationship between the oil price and the stock market. Table 3.7 shows the coefficient estimates for Equation (3.5) for this subsample. Similar to the previous subsample, the common coefficient estimates for the no-spillover and the spillover specifications are very similar. In addition, the estimated off-diagonal elements of $\widetilde{D}_{1}$ and $\widetilde{E}_{1}$ in the spillover specification are very close to zero. This suggests, again, that the no-spillover specification is adequate. Table 3.8 shows the LR test statistic of 2.180 , which supports this point. This table also presents the estimates for $\Phi(2,1)$, which have similar estimated values of -1.18 and 1.13. The $p$-values are less than 0.001 for both specifications, implying that the negative impact of an oil price volatility shock on real stock return is statistically significant at any reasonable Type I error rate. Therefore, we can conclude that there is, again, no significant evidence of volatility spillover between the two markets, but, again, an higher oil price volatility is correlated with negative stock returns, holding the oil price constant. In addition, comparing with the results from Miller and Ratti (2009), we find that, although the long-run relationship between the oil price and stock markets was found to be insignificant, it seems that another mechanism through the volatility of the oil price makes the link between the two markets. 


\subsubsection{Comments on evidence of structural break}

The exploratory estimation results above show important evidence about the oil price-stock returns relationship. First, it is very clear that the relationship had changed at the time of 1988:1, which is our first presumed break point. The LR tests and the t-test $p$-values on the estimates of $\Phi(2,1)$ indicate very different interaction patterns between these markets. For the first subsample, there is a volatility spillover between the oil market and the stock market, but oil price volatility is not important for stock returns if we hold the oil price constant. In contrast, for the latter two subsamples, both results show that the volatility spillover relationship between the two markets vanishes. However, interestingly, the volatility of the oil price is significantly correlated with stock returns while holding the oil price unchanged: an increase of oil price volatility has a negative impact on stock returns. Second, the estimation over the whole sample, however, does not produce such informative findings. The results show that the volatility spillover is not significant at the $5 \%$ level, which misses the findings from the first subsample; it is also shown that oil price volatility is not important to stock returns besides the impact from oil price changes, which misses the findings from the latter two subsamples. This reaffirms the importance of taking into account of potential structural breaks when estimating the model. Third, the volatility spillover relationship displayed by the first subsample seems to be unidirectional. In the estimation results of the spillover specification shown in Table 3.3, we see that the volatility spillover is mainly from the $\epsilon_{s r, t-1}^{2}$ in the oil price equation, while the rest estimates of the off-diagonal elements of $\widetilde{D}_{1}$ and $\widetilde{E}_{1}$ are effectively zeros. This implies that the "news" of stock returns from last period contributes to the oil price volatility, but the "news" of the oil price from last period contributes little to stock returns volatility.

To summarize, with the aid of the presumed structural break points identified by 
Miller and Ratti (2009), we find it necessary to consider the possibility of a structural break when estimating our model. Therefore, a more formal and often-used rollingwindow approach is applied to better study our sample using our model and more accurately detect the break point.

\subsection{Estimation Using the Rolling-Window Tech- nique}

In the previous section, through exploratory studies of different samples, we observe preliminary evidence that there is potentially a structural change of the oil price-stock returns relationship during the late 1980s. Therefore, it is important to further investigate the questions of i) If there's indeed a structural break during that time; and ii) when did the structural break happen. Andrews (1993) introduced tests to detect structural changes of parameters for nonlinear models when the break or change point is unknown. ${ }^{7}$ The method to test for an unknown structural break is developed base on a rolling-window procedure. In particular, one first decides an initial belief about range of dates where the break could be. Then, the whole sample is broken into two subsamples using the first candidate break point in the range, and one estimates each of the subsamples separately to obtain a joint likelihood. This joint likelihood is compared with the likelihood from the estimation of the whole sample to form an LR type statistic. After that, the whole sample is broken into two subsamples using the second candidate break point and the estimations are repeated to obtain another LR type statistic. The process continues until we have all the LR type statistics computed based on all the candidate break points. To test for the structural break, the test statistic is the largest one among all the LR type

\footnotetext{
${ }^{7}$ The methodology and initial critical values were presented in the original paper, and the critical values were corrected later in Andrews (2003).
} 
statistics, and it is compared against the table provided by Andrews (2003). If the null hypothesis that there is no structural break is rejected, then we conclude that there is significant evidence for a structural break, and the date associated with the test statistic is the most likely break point. Otherwise, we conclude that there is no strong evidence of a structural break. Additionally, the critical values do not only depend on the degrees of freedom, but also a parameter $\lambda$, which is determined by the position of the range of the candidate breaks in the whole sample. ${ }^{8}$

Using the tests provided by Andrews (1993), not only are we able to detect whether or not there is indeed a structural break during the late-1980s, but we can also determine the likely date of the break. As we believe that the structural change happened during the late-1980s, we use a range of before 1985:1 to after 1990:1. With the whole sample of 463 observations (1973:1-2011:7), this will give us a $\lambda$ that is close to 3.45 , for which the critical values are tabulated. Comparing our two specifications, the restrictions we put on the no-spillover model are that the off-diagonal elements of the $2 \times 2$ matrices $\widetilde{D}_{1}$ and $\widetilde{E}_{1}$ are zeros. Therefore, the degree of freedom for the structural break test is 4 .

\subsubsection{The results}

The rolling-window estimations are conducted and the change point of parameter is found to be after $1987: 5$ with a test statistic of 287.08 , which is significant at any reasonable type I error rate, given that the $5 \%$ critical value is 14.16 and the $1 \%$ critical value 18.42. For the whole sample log-likelihood value we use -2777.051, which is from the estimation of the whole sample based on the no-spillover specification. ${ }^{9}$ The detailed results for the subsamples of 1973:1-1987:5 and 1987:6-2011:7 are provided

\footnotetext{
${ }^{8}$ For a detailed discussion, please refer to Andrews (1993).

${ }^{9}$ We use this value because the LR test for volatility spillover for the whole sample fails to reject the null that the no-spillover specification is adequate. However, the test conclusion will not change even if we choose to use the log-likelihood value from the estimation using the spillover specification, which has a lightly larger log-likelihood.
} 
in Table 3.9 and Table 3.10, respectively. ${ }^{10}$ In these tables, the estimated parameter estimates for the GARCH process and $\Phi(2,1)$ are presented. In addition, the asymptotic left side $p$-values of the estimates of $\Phi(2,1)$ are also provided. For reference purposes, we also list the the log-likelihood values for each of the subsamples.

The estimation results for 1973:1-1987:5 are shown in Table 3.9. The spillover specification is used for estimation for this subsample. ${ }^{11}$ The first two rows show the parameter estimates for the GARCH process under the spillover specification. For the estimated matrices $\widetilde{D}_{1}$ and $\widetilde{E}_{1}$, we find that one of the eigenvalues for $\widetilde{D}_{1}+\widetilde{E}_{1}$ is within 0 and 1 , while the other one is close to 1 . This implies that the volatility on both markets during this time frame is very persistent, and this is likely because the persistent fluctuations during the 1970s. Additionally, there are several findings that are worth mentioning. First, oil price volatility is influenced by the observed past "news" and volatility of its own $\left(\epsilon_{o p, t-1}^{2}\right.$ and $\left.H_{o p, t-1}\right)$ as well as the "news" of the stock returns $\left(\epsilon_{s r, t-1}^{2}\right)$. Therefore, there is a volatility spillover from the stock market to the oil market. However, the size of the impact from its own past "news" and volatility dominates that of the spillover effect. Second, the volatility of the stock returns seems to be only affected by its own past volatility. In addition, since the coefficient estimate on the stock returns "news" term is bounded below by zero, it indicates that the volatility of stock returns depends predominantly on the overall volatility of the past rather than on the "news" from the last period only. Third, the coefficient estimates on the two oil price terms in the stock returns equation are about -0.0015 and 0.01 , which implies that the volatility spillover from the oil market to the stock markets is negligible. This is consistent with our results presented for the exploratory estimation using presumed break points in the previous section.

\footnotetext{
${ }^{10}$ In order to check robustness of the results, we also estimated our model with $p=11$ and $p=13$, and the results are qualitatively similar. It is worth noting that the results for $p=2$ are dramatically different, and this is likely because the small lag order does not account for enough seasonality.

${ }^{11}$ The LR test rejects the null hypothesis that the no-spillover specification is adequate at $5 \%$ level.
} 
Therefore, the volatility spillover between the oil market and the stock market does seem to be unidirectional, i.e. from stock market to the oil market, but not in the other direction.

The estimate of the coefficient $\Phi(2,1)$ is -0.0015 with an asymptotic left side $p$-value of 0.49 , implying that the coefficient is not statistically significant at any reasonable type I error rate. This result, however, should be carefully interpreted since the value of $\Phi(2,1)$ states the impact of the oil price volatility term on the combination of oil price changes and stock returns, given that $A(2,1) \neq 0$. To find evidence of the impact of a change of oil price volatility on stock returns, we estimate an additional version of our model with the constraint $\Phi(2,1)=A(2,1) \Phi(1,1)$. Then we use an LR test to determine if there is evidence that a change in oil price volatility significantly affects stock returns. That is, if the LR test fails the reject the constrained model, we conclude that there is no significant impact of oil price volatility on stock returns; if, however, the constrained model is rejected, then we conclude that the impact of oil price volatility on stock returns is significant, and we can estimate the impact of a change of oil price volatility on stock returns using $\Phi(2,1)-A(2,1) \Phi(1,1)$. Given the constraint, the LR test should be conducted using the $\chi^{2}(1)$ critical values. $^{12}$

The LR test statistic for this time period is well above 15. Compared with the critical value at the $5 \%$ level, 3.84 , we reject at $5 \%$ the constrained model and conclude that oil price volatility has a significant impact on stock returns, despite that the estimated $\Phi(2,1)$ is not significant at $5 \%$. Further, given the estimates of $A(2,1)=$ 0.01 and $\Phi(1,1)=0.25$, the evidence seems to imply an indirect channel through which oil price volatility affects stock returns. Although oil price volatility does not significantly depress stock returns $(\Phi(2,1)$ being insignificant at $5 \%)$ holding oil price changes constant, given that higher oil price volatility is correlated with higher oil prices $(\Phi(1,1)=0.25$ being positive) and that $A(2,1)$ is positive, we may conclude

\footnotetext{
${ }^{12} \mathrm{~A}$ detailed derivation is provided in Appendix 3.B.
} 
that oil price volatility affects stock returns negatively, but through the channel of higher oil prices. To summarize the findings during this time period, we find that the volatilities of the oil price and stock returns during this time largely depend upon the past volatility of their own, with a unidirectional volatility spillover going from the stock market to the oil market. Further, an increase in oil price volatility seems to negatively affect stock returns through the channel of its correlation with higher oil prices.

The estimation results for 1987:6-2011:7 are shown in Table 3.10. The no-spillover specification is used for estimation for this time period. ${ }^{13}$ The first two rows of the table show the GARCH coefficient estimates. Again, there are several interesting observations that are worth discussing. First, the dependence of oil price volatility seems to have shifted weights on the lagged "news" and volatility terms. After 1987:6, the difference between the coefficient estimates on the lagged squared error term and the lagged conditional forecast error variance term is larger (0.18 vs. 0.64), while before $1987: 5$ it is smaller (0.60 vs. 0.50). In other words, the volatility of the oil price depends upon the two lagged terms more equally before 1987:5, while it more heavily depends upon the past volatility than the "news" afterwards. Second, for the stock returns volatility equation, the coefficient estimates imply that the "news" in last period becomes more important in determining the volatility of stock returns after 1987:6 (0.18) than before (0). The coefficient estimates on $H_{s r, t-1}$ are similar for the two subsamples.

Another change from before 1987:5 to after 1987:6 is the estimate of $\Phi(2,1)$. It is significantly larger in magnitude than that from the first subsample. More importantly, the asymptotic left side $p$-value (0.015) suggests that the estimate is significantly negative at 5\% level. This shows that, for the time period after 1987:5,

\footnotetext{
${ }^{13}$ The LR test fails to reject the null hypothesis that the no-spillover specification is adequate at $5 \%$ level. Therefore, in each of the two GARCH equations, we do not have GARCH coefficient estimates on the terms related to the other market.
} 
oil price volatility affects stock returns negatively even holding the oil price unchanged. Given the estimates of $\Phi(1,1)=1.22$ and $A(2,1)=0.05$, there again seems to be some impact from an increase of oil price volatility on stock returns going through the channel of higher oil prices. However, oil price volatility seems to have become more important to the stock market since even holding the oil price constant, oil price volatility still has a negative impact on stock returns. Comparing with the results from the previous subsample, we can see a structural change for the oil pricestock returns relationship. Until 1987:5, oil price volatility has not been important to stock returns other than negatively affecting stock returns through the channel of its correlation with higher oil prices. And stock returns volatility has spillover effects on oil price volatility during this time. However, after 1987:6, the volatility spillover goes away, but oil price volatility becomes more imporant to the stock market that it even negatively affects stock returns if we hold the oil price constant.

\subsubsection{Comments on the empirical evidence on the relationship between oil price volatility and real stock returns}

There have been several studies focusing on the spillover effects between the energy markets and the equity markets in different contexts, and our results obtained using the rolling-window approach contributed to the literature with interesting findings about the relationship between the stock market in the US and the crude oil market.

First of all, our model detects a well pronounced structural break between 1987:5 and 1987:6, and the oil price-stock returns relationship is very different for the time before and after. There have been some studies on the topic of the oil market-equity market volatility spillovers, however, very few have directed attention to the change of the relationship involved. Malik and Hammoudeh (2007) studied the volatility spillover among the oil market and US and Gulf equity markets, using daily data from 1994:2 to 2001:12. They found "significant interaction" between the oil market 
and equity market volatilities. Malik and Ewing (2009) studied the volatility spillover between the oil price and the stock returns in different sectors using weekly data from 1992 to 2008. Their results show that all but the technology sectoral stock returns volatility affect the oil market volatility, while the oil market volatility affects all but the financials and industrials stock returns. Compared with these studies, our results provide a more comprehensive understanding in a different modeling context of the oil price-stock returns volatility spillover relationship, given the longer time period of our sample and the S\&P 500 stock index we use. In addition, our data are monthly, which is a lower frequency compared to the majority of literature, which uses weekly or daily data. The different model setup allows us to detect the volatility spillover effects in a more inclusive environment, i.e. we also allow volatility to affect the levels of the variables. The longer sample period we use also makes it possible to detect the structural break for the relationship in a wider time span. Our data frequency is lower, and it therefore provides a more "aggregate" view of the relationship. Unlike the findings in the papers above, we found no significant volatility spillover between the two markets from 1992 to 2008. However, the oil price volatility has a significant negative impact on stock returns. Our findings, therefore, provide a different angle of looking at the oil price-stock returns relationship and therefore improves the understanding in this area.

Second, our research finds an important volatility spillover relationship between the oil market and the stock market before 1987:5, and it seems to be unidirectional from the stock market to the oil market. However, the volatility spillover relationship vanishes after 1987:6. For the volatility spillover relationship, the break point detected around the middle of 1987 is also in line with several events around that time, which may be responsible for the structural change. Both the oil and stock market experienced very dramatic changes before or around the change point we find. For the oil market, the OPEC collapsed in late 1985 which caused the oil price to plum- 
met during the next few years. Although the collapse of OPEC is about one and a half years before the structural break we identified, it still could be a potential cause since the oil price recovered a considerable portion of the plunge during the next one year or so, as the OPEC members started to comply to the production quotas. Our break point then indicates that the oil market may have changed at least since the recovery, if not the collapse. In particular, the oil price volatility became less subject to the "news" in the stock market after the change. However, a more important factor that may play a role causing the structural break could be the Tax Reform Act in 1986 in the US, which has direct impact on investment incentives. Edelstein and Kilian (2007) stated that the Act had a depressing impact on investors' decisions to invest and changed their investment spending behavior despite the falling energy price around that time. Further, the authors also suggested that the short-term impact of the Tax Reform Act could remain in effect till as late as the fourth quarter of 1987. Therefore, we have good reasons to believe that the Tax Reform Act, which exercised negative pressures on investment activities, could have shifted the stock market volatility structures. Lastly, the timing of the break point also stirs our memory of the black Monday of October 19, 1987, when the stock market crashed, although it is about 5 months earlier. There has been discussions about the causes of the crash and the major reasons seems to be the margin calls, program trading, and bad information (see, for example, Carlson (2007)). The Federal Reserve took several measures to eventually stabilize the turmoil in the financial markets, but the financial system of the US still took a big shock. Several remedial measures were put forth after the crash aiming to better regulate the stock market and increase information availability. Therefore, we believe that the new changes to the stock market also limited the volatility spillover towards the oil market.

Third, for the relationship between the oil price volatility and stock returns, the break point we detected after 1987:5 can be viewed as a change in the investment 
options available to investors. Research on alternative energy resources was heating up during the late 1980s in light of many countries' effort to reduce oil dependency. Many companies were created during this time to provide clean energy or alternative energy and they gradually became traded on the stock market. Therefore, when the oil price experience large volatility, there will be shift in investment to new energy companies from the other sectors on the stock market. However, the S\&P 500 index has only $12.7 \%$ of energy components, of which an even smaller portion would be the new energy sector. Therefore, this shift could potentially drive down the overall stock index returns. Given that the returns in the new energy sector would be likely to increase, however, the decrease impact may be dampened. This is also consistent with the size of our estimate of $\Phi(2,1)=-0.20$, which indicates that a one unit increase of the conditional forecast standard deviation increases is correlated to about a $0.2 \%$ decrease of the stock index returns, holding the oil price constant. Additionally, the change from "stock volatility" affecting "oil volatility" to "oil volatility" affecting "stock returns" seems to indicate that the US has become a price taker rather than a price maker due, perhaps, to the growing demand for oil in Europe and Asia as well as growing internationalization of trade.

Finally, the results from our study complement the results of Miller and Ratti (2009), which detected structural breaks in the long-run relationship between oil and stock. Our results shown in previous sections identify another source of correlation between oil price fluctuations and real stock returns.

\subsection{Concluding Remarks and Comments on Future Work}

In this chapter, we study the relationship between the oil price and real stock returns. We use a slightly more general version of the GARCH-M VAR model found 
in Elder (2004) and Elder and Serletis (2010) to characterize the relationship between the oil price and real stock returns. The use of this model allows us to capture both the volatility spillover relationship between the two markets as well as the impact of oil price volatility on stock returns at the same time. We use the conditional forecast error standard deviation to proxy the volatility of the oil price, and the log differences of the deflated S\&P 500 index are used to represent stock returns. Our data are from 1973:1 to 2011:7. For estimation, we first estimate our model over the full sample and then over each of the subsamples determined by the structural breaks found in Miller and Ratti (2009). Based on the preliminary results, we use the rolling-window technique to detect a structural break point between 1987:5 and 1987:6. We show that the relationship between the oil price and stock returns is different before and after the break: while a unidirectional volatility spillover from the stock market to the oil market seems to be significant before the break, the correlation between oil price volatility and stock returns seems to be more pronounced after the break. Based on the results, we believe that the structural change was caused by several events taking place around that time, including the OPEC collapse in late 1985, the Tax Reform Act in 1986 in the US, and the stock market crash in late 1987.

The results of this chapter are obtained using crude oil price and a US composite stock index. It should be noted that future studies in different angles are worth pursuing. As Edelstein and Kilian (2007) stated, using crude oil price is only one aspect of the oil price, as the price of refined products from crude oil may have different information and implications. Moreover, in light of the literature that examines different sectors of the stock market, it would be useful to estimate our model using stock returns in different sectors to obtain sectoral insights of the oil price-stock returns relationship in the context of our model specification. 


\section{References}

Akgiray, V. (1989). Conditional Heteroscedasticity in Time Series of Stock Returns: Evidence and Forecasts. The Journal of Business, 62, 55-80.

Andrews, D. W. K. (1993). Tests for Parameter Instability and Structural Change With Unknown Change Point. Econometrica, 61, 821-856.

Andrews, D. W. K. (2003). Tests for Parameter Instability and Structural Change with Unknown Change Point: A Corrigendum. Econometrica, 71, 395-397.

Arouri, M. E. H. and Rault, C. (2012). Oil Prices and Stock Markets in GCC Countries: Empirical Evidence from Panel Analysis. International Journal of Finance and Economics, 17, 242-253.

Bollerslev, T. (1986). Generalized Autoregressive Conditional Heteroskedasticity. Journal of Econometrics, 31, 307-327.

Carlson, M. (2007). A Brief History of the 1987 Stock Market Crash with a Discussion of the Federal Reserve Response. Finance and Economics Discussion Series, Divisions of Research \& Statistics and Monetary Affairs, Federal Reserve Board, Washington, D.C. No. 2007-13.

Conrad, C., Loch, K., and Rittler, D. (2012). On the Macroeconomic Determinants of the Long-Term Oil-Stock Correlation. Department of Economics, University of Heidelberg: Discussion Paper No. 525.

Edelstein, P. and Kilian, L. (2007). The Response of Business Fixed Investment to Changes in Energy Prices: A Test of Some Hypotheses About the Transmission of Energy Price Shocks. The B.E. Journal of Macroeconomics, 7. 
Elder, J. (2004). Another Perspective on the Effects of Inflation Uncertainty. Journal of Money, Credit and Banking, 36, 911-928.

Elder, J. and Serletis, A. (2010). Oil Price Uncertainty. Journal of Money, Credit and Banking, 42, 1137-1159.

Engle, R. F. (1982). Autoregressive Conditional Heteroscedasticity with Estimates of the Variance of United Kingdom Inflation. Econometrica, 50, 987-1007.

Engle, R. F. and Kroner, K. F. (1995). Multivariate Simultaneous Generalized ARCH. Econometric Theory, 11, 122-150.

Fayyad, A. and Daly, K. (2011a). International Transmission of Stock Returns: Mean and Volatility Spillover Effects in the Emerging Markets of the GCC Countries, the Developed Markets of UK \& USA and Oil. International Research Journal of Finance and Economics, 13, 103-117.

Fayyad, A. and Daly, K. (2011b). The Impact of Oil Price Shocks on Stock Market Returns: Comparing GCC Countries with the UK and USA. Emerging Markets Review, 12, 61-78.

Federer, J. P. (1996). Oil Price Volatility and the Macroeconomy. Journal of Macroeconomics, 18, 1-26.

Filis, G. (2010). Macro Economy, Stock Market and Oil Prices: Do Meaningful Relationships Exist among Their Cyclical Fluctuations? Energy Economics, 32, $877-886$.

Filis, G., Degiannakis, S., and Floros, C. (2011). Dynamic Correlation between Stock Market and Oil Prices: The Case of Oil-Importing and Oil-Exporting Countries. International Review of Financial Analysis, 20, 152-164. 
Guo, H. and Kliesen, K. L. (2005). Oil Price Volatility and U.S. Macroeconomic Activity. Federal Reserve Bank of St. Louis Review, 87, 669-683.

Hooker, M. A. (1996). What Happened to the Oil Price-Macroeconomy Relationship? Journal of Monetary Economics, 38, 195-213.

Huang, R. D., Masulis, R. W., and Stoll, H. R. (1996). Energy Shocks and Financial Markets. Journal of Futures Markets, 16, 1-27.

Jammazi, R. (2012). Oil Shock Transmission to Stock Market Returns: WaveletMultivariate Markov Switching GARCH Approach. Energy, 37, 430-454.

Jammazi, R. and Aloui, C. (2010). Wavelet Decomposition and Regime Shifts: Assessing the Effects of Crude Oil Shocks on Stock Market Returns. Energy Policy, 38, 1415-1435.

Jones, C. M. and Kaul, G. (1996). Oil and the Stock Markets. The Journal of Finance, 51, 463-491.

Kapusuzoglu, A. (2011). Relationships between Oil Price and Stock Market: An Empirical Analysis from Istanbul Stock Exchange (ISE). International Journal of Economics and Finance, 3, 99-106.

Kapusuzoglu, A. and Karan, M. B. (2011). An Analysis of the Relationships between Financial Indicators and Energy Prices among the OECD Countries. International Journal of Business and Social Science, 2, 258-274.

Kilian, L. and Park, C. (2009). The Impact of Oil Price Shocks on the U.S. Stock Market. International Economic Review, 50, 1267-1287.

Lee, K., Ni, S., and Ratti, R. A. (1995). Oil Shocks and the Macroeconomy: The Role of Price Variability. The Energy Journal, 16, 39-56. 
Malik, F. and Ewing, B. T. (2009). Volatility Transmission between Oil Prices and Equity Sector Returns. International Review of Financial Analysis, 18, 95-100.

Malik, F. and Hammoudeh, S. (2007). Shock and Volatility Transmission in the Oil, US and Gulf Equity Markets. International Review of Economics and Finance, 16, $357-368$.

Miller, J. I. and Ni, S. (2011). Long-Term Oil Price Forecasts: A New Perspective on Oil and the Macroeconomy. Macroeconomic Dynamics, 15(S3), 396-415.

Miller, J. I. and Ratti, R. A. (2009). Crude Oil and Stock Markets: Stability, Instability, and Bubbles. Energy Economics, 31, 559-568.

Rahman, S. and Serletis, A. (2011). The Asymmetric Effects of Oil Price Shocks. Macroeconomic Dynamics, 15(S3), 437-471.

Sadorsky, P. (1999). Oil Price Shocks and Stock Market Activity. Energy Economics, 21, 449-469.

Zhang, C. and Chen, X. (2011). The Impact of Global Oil Price Shocks on China's Stock Returns: Evidence from the ARJI $\left(-h_{t}\right)$-EGARCH Model. Energy, 36, 66276633.

Zhu, H.-M., Li, S.-F., and Yu, K. (2011). Crude Oil Shocks and Stock Markets: A Panel Threshold Cointegration Approach. Energy Economics, 33, 987-994. 


\section{Appendix 3.A: The Derivation of the Simplified GARCH Specification}

From Equation (3.2), we have

$$
\operatorname{vec}\left(H_{t}\right)=C^{*}+\sum_{i=1}^{m} D_{i}^{*} \operatorname{vec}\left(\epsilon_{t-i} \epsilon_{t-i}^{\prime}\right)+\sum_{j=1}^{k} E_{j}^{*} \operatorname{vec}\left(H_{t-j}\right)
$$

This equation can be alternatively written as

$$
\operatorname{vec}\left(H_{t}\right)=\operatorname{vec}\left(C C^{\prime}\right)+\sum_{i=1}^{m}\left(D_{i} \otimes D_{i}\right) \operatorname{vec}\left(\epsilon_{t-i} \epsilon_{t-i}^{\prime}\right)+\sum_{j=1}^{k}\left(E_{j} \otimes E_{j}\right) \operatorname{vec}\left(H_{t-j}\right)
$$

where the matrices $C, D_{i}$ 's, and $E_{j}$ 's are the coefficient matrices in the following equation:

$$
H_{t}=C C^{\prime}+\sum_{i=1}^{m} D_{i} \epsilon_{t-i} \epsilon_{t-i}^{\prime} D_{i}^{\prime}+\sum_{j=1}^{m} E_{j} H_{t-j} E_{j}^{\prime}
$$

Using usual notations for the elements in a matrix, we have

$$
\begin{aligned}
(D \otimes D) \operatorname{vec}\left(\epsilon \epsilon^{\prime}\right)= & {\left[\begin{array}{llll}
d_{11} d_{11} & d_{11} d_{12} & d_{12} d_{11} & d_{12} d_{12} \\
d_{11} d_{21} & d_{11} d_{22} & d_{12} d_{21} & d_{12} d_{22} \\
d_{21} d_{11} & d_{21} d_{12} & d_{22} d_{11} & d_{22} d_{12} \\
d_{21} d_{21} & d_{21} d_{22} & d_{22} d_{21} & d_{22} d_{22}
\end{array}\right]\left[\begin{array}{c}
\epsilon_{1}^{2} \\
\epsilon_{1} \epsilon_{2} \\
\epsilon_{1} \epsilon_{2} \\
\epsilon_{2}^{2}
\end{array}\right] } \\
& =\left[\begin{array}{llll}
d_{11} d_{11} & d_{11} d_{12} & d_{12} d_{11} & d_{12} d_{12} \\
d_{11} d_{21} & d_{11} d_{22} & d_{12} d_{21} & d_{12} d_{22} \\
d_{21} d_{11} & d_{21} d_{12} & d_{22} d_{11} & d_{22} d_{12} \\
d_{21} d_{21} & d_{21} d_{22} & d_{22} d_{21} & d_{22} d_{22}
\end{array}\right]\left[\begin{array}{c}
\epsilon_{1}^{2} \\
0 \\
0 \\
\epsilon_{2}^{2}
\end{array}\right],
\end{aligned}
$$

where the index $i$ is suppressed for notational convenience. The last part of the equation follows the assumption that the errors are contemporaneously uncorrelated. 
Similarly,

$$
(E \otimes E) \operatorname{vec}(H)=\left[\begin{array}{cccc}
e_{11} e_{11} & e_{11} e_{12} & e_{12} e_{11} & e_{12} e_{12} \\
e_{11} e_{21} & e_{11} e_{22} & e_{12} e_{21} & e_{12} e_{22} \\
e_{21} e_{11} & e_{21} e_{12} & e_{22} e_{11} & e_{22} e_{12} \\
e_{21} e_{21} & e_{21} e_{22} & e_{22} e_{21} & e_{22} e_{22}
\end{array}\right]\left[\begin{array}{c}
h_{11} \\
0 \\
0 \\
h_{22}
\end{array}\right]
$$

where, again, the time index $j$ has been suppressed. In addition,

$$
\operatorname{vec}\left(C C^{\prime}\right)=\operatorname{vec}\left(\left[\begin{array}{ll}
c_{11} & c_{12} \\
c_{21} & c_{22}
\end{array}\right]\left[\begin{array}{cc}
c_{11} & c_{21} \\
c_{12} & c_{22}
\end{array}\right]\right)=\operatorname{vec}\left[\begin{array}{cc}
c_{11}^{2}+c_{12}^{2} & c_{11} c_{21}+c_{12} c_{22} \\
c_{11} c_{21}+c_{12} c_{22} & c_{21}^{2}+c_{22}^{2}
\end{array}\right]
$$

If we assume $c_{12}=c_{21}=0$, which also implies that $c_{11} c_{21}=c_{12} c_{22}=0$, then

$$
\operatorname{vec}\left(C C^{\prime}\right)=\operatorname{vec}\left(\begin{array}{cc}
c_{11}^{2} & 0 \\
0 & c_{22}^{2}
\end{array}\right)
$$

(continued on the next page) 
Therefore, with time indices $t, i$, and $j$ suppressed for convenience, Equation (3.2) can be written as

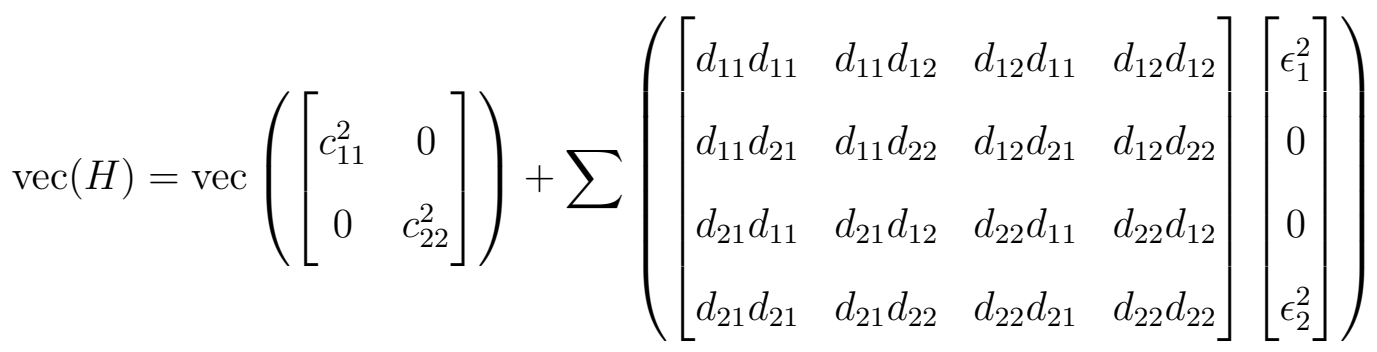

$$
\begin{aligned}
& +\sum\left(\left[\begin{array}{cccc}
e_{11} e_{11} & e_{11} e_{12} & e_{12} e_{11} & e_{12} e_{12} \\
e_{11} e_{21} & e_{11} e_{22} & e_{12} e_{21} & e_{12} e_{22} \\
e_{21} e_{11} & e_{21} e_{12} & e_{22} e_{11} & e_{22} e_{12} \\
e_{21} e_{21} & e_{21} e_{22} & e_{22} e_{21} & e_{22} e_{22}
\end{array}\right]\left[\begin{array}{c}
h_{11} \\
0 \\
0 \\
h_{22}
\end{array}\right]\right) \\
& =\operatorname{vec}\left(\left[\begin{array}{cc}
c_{11}^{2} & 0 \\
0 & c_{22}^{2}
\end{array}\right]\right) \\
& +\sum\left(\left[\begin{array}{llll}
d_{11} d_{11} & d_{11} d_{12} & d_{12} d_{11} & d_{12} d_{12} \\
d_{11} d_{21} & d_{11} d_{22} & d_{12} d_{21} & d_{12} d_{22} \\
d_{21} d_{11} & d_{21} d_{12} & d_{22} d_{11} & d_{22} d_{12} \\
d_{21} d_{21} & d_{21} d_{22} & d_{22} d_{21} & d_{22} d_{22}
\end{array}\right]\left[\begin{array}{cccc}
1 & 0 & 0 & 0 \\
0 & 0 & 0 & 0 \\
0 & 0 & 0 & 0 \\
0 & 0 & 0 & 1
\end{array}\right] \operatorname{vec}\left(\epsilon \epsilon^{\prime}\right)\right) \\
& +\sum\left(\left[\begin{array}{cccc}
e_{11} e_{11} & e_{11} e_{12} & e_{12} e_{11} & e_{12} e_{12} \\
e_{11} e_{21} & e_{11} e_{22} & e_{12} e_{21} & e_{12} e_{22} \\
e_{21} e_{11} & e_{21} e_{12} & e_{22} e_{11} & e_{22} e_{12} \\
e_{21} e_{21} & e_{21} e_{22} & e_{22} e_{21} & e_{22} e_{22}
\end{array}\right]\left[\begin{array}{cccc}
1 & 0 & 0 & 0 \\
0 & 0 & 0 & 0 \\
0 & 0 & 0 & 0 \\
0 & 0 & 0 & 1
\end{array}\right] \operatorname{vec}(H)\right)
\end{aligned}
$$

(continued on the next page) 
Now use the identity that

$$
\left[\begin{array}{llll}
1 & 0 & 0 & 0 \\
0 & 0 & 0 & 0 \\
0 & 0 & 0 & 0 \\
0 & 0 & 0 & 1
\end{array}\right]=\left[\begin{array}{ll}
1 & 0 \\
0 & 0 \\
0 & 0 \\
0 & 1
\end{array}\right]\left[\begin{array}{llll}
1 & 0 & 0 & 0 \\
0 & 0 & 0 & 1
\end{array}\right],
$$

and we obtain

$$
\begin{aligned}
& \operatorname{vec}(H)=\operatorname{vec}\left(\left[\begin{array}{cc}
c_{11}^{2} & 0 \\
0 & c_{22}^{2}
\end{array}\right]\right) \\
& +\sum\left(\left[\begin{array}{llll}
d_{11} d_{11} & d_{11} d_{12} & d_{12} d_{11} & d_{12} d_{12} \\
d_{11} d_{21} & d_{11} d_{22} & d_{12} d_{21} & d_{12} d_{22} \\
d_{21} d_{11} & d_{21} d_{12} & d_{22} d_{11} & d_{22} d_{12} \\
d_{21} d_{21} & d_{21} d_{22} & d_{22} d_{21} & d_{22} d_{22}
\end{array}\right]\left[\begin{array}{ll}
1 & 0 \\
0 & 0 \\
0 & 0 \\
0 & 1
\end{array}\right]\right) \\
& +\sum\left(\left[\begin{array}{llll}
e_{11} e_{11} & e_{11} e_{12} & e_{12} e_{11} & e_{12} e_{12} \\
e_{11} e_{21} & e_{11} e_{22} & e_{12} e_{21} & e_{12} e_{22} \\
e_{21} e_{11} & e_{21} e_{12} & e_{22} e_{11} & e_{22} e_{12} \\
e_{21} e_{21} & e_{21} e_{22} & e_{22} e_{21} & e_{22} e_{22}
\end{array}\right]\left[\begin{array}{ll}
1 & 0 \\
0 & 0 \\
0 & 0 \\
0 & 1
\end{array}\right]\left[\begin{array}{llll}
1 & 0 & 0 & 0 \\
0 & 0 & 0 & 1
\end{array}\right] \operatorname{vec}(H)\right) \text {. }
\end{aligned}
$$

Note that for a generic $2 \times 2$ matrix $M$, we have

$$
\left[\begin{array}{llll}
1 & 0 & 0 & 0 \\
0 & 0 & 0 & 1
\end{array}\right] \operatorname{vec}(M)=\operatorname{diag}(M)
$$

(continued on the next page) 
Therefore,

$$
\begin{aligned}
& \operatorname{diag}(H)=\left[\begin{array}{llll}
1 & 0 & 0 & 0 \\
0 & 0 & 0 & 1
\end{array}\right] \operatorname{vec}(H) \\
& =\left[\begin{array}{llll}
1 & 0 & 0 & 0 \\
0 & 0 & 0 & 1
\end{array}\right] \operatorname{vec}\left(C C^{\prime}\right) \\
& \left.+\sum\left[\begin{array}{llll}
1 & 0 & 0 & 0 \\
0 & 0 & 0 & 1
\end{array}\right](D \otimes D)\left[\begin{array}{ll}
1 & 0 \\
0 & 0 \\
0 & 0 \\
0 & 1
\end{array}\right]\left[\begin{array}{llll}
1 & 0 & 0 & 0 \\
0 & 0 & 0 & 1
\end{array}\right] \operatorname{vec}\left(\epsilon \epsilon^{\prime}\right)\right) \\
& +\sum\left(\left[\begin{array}{llll}
1 & 0 & 0 & 0 \\
0 & 0 & 0 & 1
\end{array}\right](E \otimes E)\left[\begin{array}{ll}
1 & 0 \\
0 & 0 \\
0 & 0 \\
0 & 1
\end{array}\right]\left[\begin{array}{llll}
1 & 0 & 0 & 0 \\
0 & 0 & 0 & 1
\end{array}\right] \operatorname{vec}(H)\right. \\
& =\left[\begin{array}{c}
c_{11}^{2} \\
c_{22}^{2}
\end{array}\right]+\sum\left(\left[\begin{array}{ll}
d_{11}^{2} & d_{12}^{2} \\
d_{21}^{2} & d_{22}^{2}
\end{array}\right] \operatorname{diag}\left(\epsilon \epsilon^{\prime}\right)\right)+\sum\left(\left[\begin{array}{cc}
e_{11}^{2} & e_{12}^{2} \\
e_{21}^{2} & e_{22}^{2}
\end{array}\right] \operatorname{diag}(H)\right) \text {. }
\end{aligned}
$$

Let

$$
\widetilde{C}=\left[\begin{array}{c}
c_{11}^{2} \\
c_{22}^{2}
\end{array}\right], \quad \widetilde{D}=\left[\begin{array}{ll}
d_{11}^{2} & d_{12}^{2} \\
d_{21}^{2} & d_{22}^{2}
\end{array}\right], \quad \widetilde{E}=\left[\begin{array}{ll}
e_{11}^{2} & e_{12}^{2} \\
e_{21}^{2} & e_{22}^{2}
\end{array}\right]
$$

and rewrite the above results with time indices, we have

$$
\operatorname{diag}\left(H_{t}\right)=\widetilde{C}+\sum_{i=1}^{m} \widetilde{D}_{i} \operatorname{diag}\left(\epsilon_{t-i} \epsilon_{t-i}^{\prime}+\sum_{j=1}^{k} \widetilde{E}_{j} \operatorname{diag}\left(H_{t-j}\right)\right.
$$

which is Equation (3.5). 


\section{Appendix 3.B: The Rationale of the LR Test to Isolate the Impact of Oil Price Volatility on Stock Returns}

Equation (3.1) can be written as

$$
\left[\begin{array}{cc}
1 & 0 \\
a_{21} & 1
\end{array}\right]\left[\begin{array}{c}
\Delta \ln p_{t} \\
r_{t}
\end{array}\right]=\mathbb{Y}_{t-1}+\left[\begin{array}{ll}
\phi_{11} & \phi_{12} \\
\phi_{21} & \phi_{22}
\end{array}\right]\left[\begin{array}{c}
H_{o p, t}^{1 / 2} \\
H_{s r, t}^{1 / 2}
\end{array}\right]
$$

where $\mathbb{Y}_{t-1}=\left[\mathbb{Y}_{1, t-1}, \mathbb{Y}_{2, t-1}\right]^{\prime}$ contains the autoregressive part on the right hand side of the equation. This implies the two equations below:

$$
\begin{array}{r}
\Delta \ln p_{t}=\mathbb{Y}_{1, t-1}+\phi_{11} H_{o p, t}^{1 / 2}+\phi_{12} H_{s r, t}^{1 / 2}, \\
a_{21} \Delta \ln p_{t}+r_{t}=\mathbb{Y}_{2, t-1}+\phi_{21} H_{o p, t}^{1 / 2}+\phi_{22} H_{s r, t}^{1 / 2} .
\end{array}
$$

Multiply both sides of the first equation by $a_{21}$, and subtract it from the second equation, we have

$$
r_{t}=\left(\mathbb{Y}_{2, t-1}-a_{21} \mathbb{Y}_{1, t-1}\right)+\left(\phi_{21}-a_{21} \phi_{11}\right) H_{o p, t}^{1 / 2}+\left(\phi_{22}-a_{21} \phi_{12}\right) H_{s r, t}^{1 / 2}
$$

Therefore, the hypothesis $\phi_{21}-a_{21} \phi_{11}=0$, or $\phi_{21}=a_{21} \phi_{11}$, implies that there is no impact of oil price volatility on stock returns when holding the oil price constant. However, if this hypothesis is rejected, we then conclude that oil price volatility has impact on stock returns even when holding the oil price constant, and the estimate of the size of the impact is $\phi_{21}-a_{21} \phi_{11}$. 


\section{Appendix 3.C: Figures and Tables of Chapter 3}

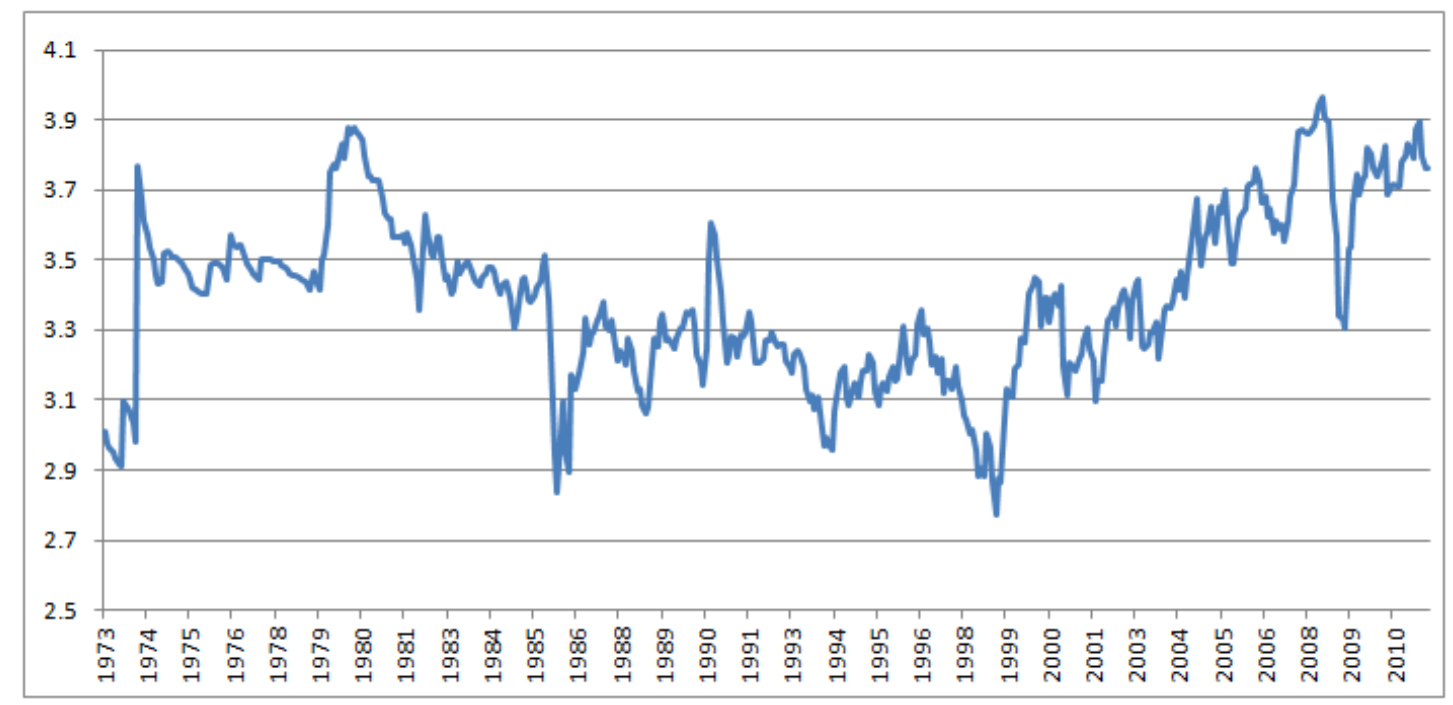

Figure 3.1: Plot of Real Oil Price, monthly, 1973.1-2011.7: The WTI oil prices are deflated by PPI and are in natural logs.

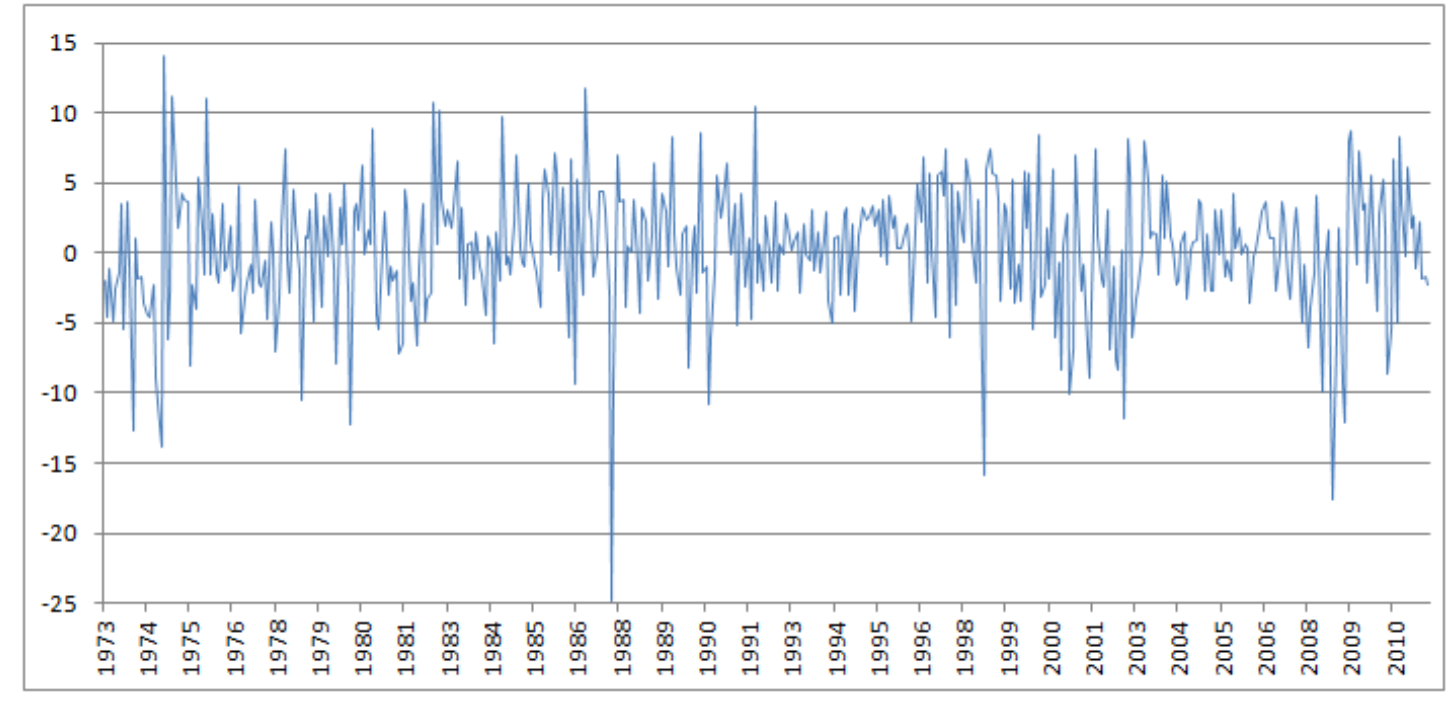

Figure 3.2: Plot of Real Stock Return, monthly, 1973.1-2011.7: The S\&P 500 index series are deflated by CPI and the returns are calculated by log differences. 


\begin{tabular}{c|l|c|c|c|c|c}
\hline \hline Model & Variance equation & Constant & $\epsilon_{o p, t-1}^{2}$ & $\epsilon_{s r, t-1}^{2}$ & $H_{o p, t-1}$ & $H_{s r, t-1}$ \\
\hline \multirow{2}{*}{ No-spillover } & Oil price & 7.38 & 0.60 & - & 0.39 & - \\
\cline { 2 - 7 } & Real stock returns & 3.81 & - & 0.12 & - & 0.69 \\
\hline \multirow{2}{*}{ Spillover } & Oil price & 7.35 & 0.60 & 0.29 & 0.28 & -0.001 \\
\cline { 2 - 7 } & Real stock returns & 3.76 & -0.001 & 0.10 & 0.01 & 0.68 \\
\hline \hline
\end{tabular}

Table 3.1: Coefficient estimates for the GARCH process characterized in Equation (3.5). Sample from 1973:1 to 2011:7. Note: $\epsilon_{o p, t-1}^{2}$ and $\epsilon_{s r, t-1}^{2}$ are the components of $\operatorname{diag}\left(\epsilon_{t-1} \epsilon_{t-1}^{\prime}\right)$ for the oil price and stock returns, respectively; $H_{o p, t-1}$ and $H_{s r, t-1}$ are the components of $\operatorname{diag}\left(H_{t-1}\right)$ for the oil price and stock returns, respectively.

\begin{tabular}{l|c|c}
\hline \hline Model & $\Phi(2,1)$ & Log Likelihood \\
\hline No-spillover & $-0.044(0.22)$ & -2777.014 \\
\hline Spillover & $0.009(0.57)$ & -2772.840 \\
\hline Likelihood Ratio & \multicolumn{2}{|c}{8.348} \\
\hline \hline
\end{tabular}

Table 3.2: The coefficient estimates for $\Phi(2,1)$ with the asymptotic left side $p$-values in parentheses. Sample from 1973:1 to 2011:7. Log likelihood values and the likelihood ratio test statistic is also provided. $\chi_{0.05}^{2}(4)=9.488$ and $\chi_{0.01}^{2}(4)=13.28$. 


\begin{tabular}{c|l|c|c|c|c|c}
\hline \hline Model & Variance equation & Constant & $\epsilon_{o p, t-1}^{2}$ & $\epsilon_{s r, t-1}^{2}$ & $H_{o p, t-1}$ & $H_{s r, t-1}$ \\
\hline \multirow{2}{*}{ No-spillover } & Oil price & 7.36 & 0.60 & - & 0.37 & - \\
\cline { 2 - 7 } & Real stock returns & 3.93 & - & -0.0014 & - & 0.82 \\
\hline \multirow{2}{*}{ Spillover } & Oil price & 0.01 & 0.60 & 0.09 & 0.52 & -0.001 \\
\cline { 2 - 7 } & Real stock returns & 4.07 & -0.0005 & -0.0004 & -0.001 & 0.80 \\
\hline \hline
\end{tabular}

Table 3.3: Coefficient estimates for the GARCH process characterized in Equation (3.5). Sample from 1973:1 to 1988:1. Note: $\epsilon_{o p, t-1}^{2}$ and $\epsilon_{s r, t-1}^{2}$ are the components of $\operatorname{diag}\left(\epsilon_{t-1} \epsilon_{t-1}^{\prime}\right)$ for the oil price and stock returns, respectively; $H_{o p, t-1}$ and $H_{s r, t-1}$ are the components of $\operatorname{diag}\left(H_{t-1}\right)$ for the oil price and stock returns, respectively.

\begin{tabular}{l|c|c}
\hline \hline Model & $\Phi(2,1)$ & Log Likelihood \\
\hline No-spillover & $-0.057(0.22)$ & -1050.530 \\
\hline Spillover & $-0.044(0.23)$ & -1045.240 \\
\hline Likelihood Ratio & \multicolumn{2}{|c}{10.580} \\
\hline \hline
\end{tabular}

Table 3.4: The coefficient estimates for $\Phi(2,1)$ with the asymptotic left side $p$-values in parentheses. Sample from 1973:1 to 1988:1. Log likelihood values and the likelihood ratio test statistic is also provided. $\chi_{0.05}^{2}(4)=9.488$ and $\chi_{0.01}^{2}(4)=13.28$. 


\begin{tabular}{c|l|c|c|c|c|c}
\hline \hline Model & Variance equation & Constant & $\epsilon_{o p, t-1}^{2}$ & $\epsilon_{s r, t-1}^{2}$ & $H_{o p, t-1}$ & $H_{s r, t-1}$ \\
\hline \multirow{2}{*}{ No-spillover } & Oil price & 9.80 & 0.97 & - & -0.0022 & - \\
\cline { 2 - 7 } & Real stock returns & 0.26 & - & 0.26 & - & 0.79 \\
\hline \multirow{2}{*}{ Spillover } & Oil price & 9.80 & 0.97 & 0.000 & -0.0005 & -0.000 \\
\cline { 2 - 7 } & Real stock returns & 0.26 & -0.000 & 0.26 & -0.000 & 0.79 \\
\hline \hline
\end{tabular}

Table 3.5: Coefficient estimates for the GARCH process characterized in Equation (3.5). Sample from 1988:2 to 1999:9. Note: $\epsilon_{o p, t-1}^{2}$ and $\epsilon_{s r, t-1}^{2}$ are the components of $\operatorname{diag}\left(\epsilon_{t-1} \epsilon_{t-1}^{\prime}\right)$ for the oil price and stock returns, respectively; $H_{o p, t-1}$ and $H_{s r, t-1}$ are the components of $\operatorname{diag}\left(H_{t-1}\right)$ for the oil price and stock returns, respectively. 0.000 and -0.000 indicate that the magnitudes for those estimates are effectively small and can be treated as 0 .

\begin{tabular}{l|c|c}
\hline \hline Model & $\Phi(2,1)$ & Log Likelihood \\
\hline No-spillover & $-0.771(0.001)$ & -685.926 \\
\hline Spillover & $-0.771(<0.001)$ & -684.931 \\
\hline Likelihood Ratio & \multicolumn{2}{|c}{1.990} \\
\hline \hline
\end{tabular}

Table 3.6: The coefficient estimates for $\Phi(2,1)$ with the asymptotic left side $p$-values in parentheses. Sample from 1988:2 to 1999:9. Log likelihood values and the likelihood ratio test statistic is also provided. $\chi_{0.05}^{2}(4)=9.488$ and $\chi_{0.01}^{2}(4)=13.28$. 


\begin{tabular}{c|l|c|c|c|c|c}
\hline \hline Model & Variance equation & Constant & $\epsilon_{o p, t-1}^{2}$ & $\epsilon_{s r, t-1}^{2}$ & $H_{o p, t-1}$ & $H_{s r, t-1}$ \\
\hline \multirow{2}{*}{ No-spillover } & Oil price & 7.11 & 0.50 & - & 0.37 & - \\
\cline { 2 - 7 } & Real stock returns & 1.74 & - & 0.60 & - & 0.39 \\
\hline \multirow{2}{*}{ Spillover } & Oil price & 7.11 & 0.50 & -0.0005 & 0.36 & 0.001 \\
\cline { 2 - 7 } & Real stock returns & 1.74 & -0.001 & 0.61 & -0.0003 & 0.38 \\
\hline \hline
\end{tabular}

Table 3.7: Coefficient estimates for the GARCH process characterized in Equation (3.5). Sample from 1999:10 to 2011:7. Note: $\epsilon_{o p, t-1}^{2}$ and $\epsilon_{s r, t-1}^{2}$ are the components of $\operatorname{diag}\left(\epsilon_{t-1} \epsilon_{t-1}^{\prime}\right)$ for the oil price and stock returns, respectively; $H_{o p, t-1}$ and $H_{s r, t-1}$ are the components of $\operatorname{diag}\left(H_{t-1}\right)$ for the oil price and stock returns, respectively.

\begin{tabular}{l|c|c}
\hline \hline Model & $\Phi(2,1)$ & Log Likelihood \\
\hline No-spillover & $-1.18(<0.001)$ & -751.9143 \\
\hline Spillover & $-1.13(<0.001)$ & -750.8345 \\
\hline Likelihood Ratio & \multicolumn{2}{|c}{2.180} \\
\hline \hline
\end{tabular}

Table 3.8: The coefficient estimates for $\Phi(2,1)$ with the asymptotic left side $p$-values in parentheses. Sample from 1999:10 to 2011:7. Log likelihood values and the likelihood ratio test statistic is also provided. $\chi_{0.05}^{2}(4)=9.488$ and $\chi_{0.01}^{2}(4)=13.28$. 


\begin{tabular}{l|l|c|c|c|c|c}
\hline \hline Model & Variance equation & Constant & $\epsilon_{o p, t-1}^{2}$ & $\epsilon_{s r, t-1}^{2}$ & $H_{o p, t-1}$ & $H_{s r, t-1}$ \\
\hline & Oil price & 0.01 & 0.60 & 0.10 & 0.50 & -0.00154 \\
\cline { 2 - 7 } & Real stock returns & 4.57 & -0.00145 & -0.00152 & 0.01 & 0.69 \\
\cline { 2 - 7 } Spillover & $A(2,1)$ & \multicolumn{5}{|c}{0.01} \\
\cline { 2 - 7 } & $\Phi(1,1)$ & \multicolumn{5}{|c}{-0.25} \\
\cline { 2 - 6 } & $\Phi(1,2)$ & \multicolumn{5}{|c}{$-0.0012(0.48)$} \\
\cline { 2 - 6 } & $\Phi(2,1)$ & \multicolumn{5}{|c|}{-978.0086} \\
\cline { 2 - 6 } & Log-likelihood & \multicolumn{5}{|c|}{} \\
\hline \hline
\end{tabular}

Table 3.9: The coefficient estimates for the subsample 1973:1-1987:5. Note: $\epsilon_{o p, t-1}^{2}$ and $\epsilon_{s r, t-1}^{2}$ are the components of $\operatorname{diag}\left(\epsilon_{t-1} \epsilon_{t-1}^{\prime}\right)$ for the oil price and stock returns, respectively; $H_{o p, t-1}$ and $H_{s r, t-1}$ are the components of $\operatorname{diag}\left(H_{t-1}\right)$ for the oil price and stock returns, respectively. GARCH coefficients are provided in the first two rows, below which the estimate of $A(2,1), \Phi(1,1), \Phi(1,2), \Phi(2,1)$, and the log-likelihood value are presented. The asymptotic left side $p$-values of the estimates of $\Phi(1,2)$ and $\Phi(2,1)$ are also included in the parentheses.

\begin{tabular}{|c|c|c|c|c|c|c|}
\hline Model & "Variance equation & Constant & $\overline{\overline{\epsilon_{o p, t-1}^{2}}}$ & $\overline{\overline{\epsilon_{s r, t-1}^{2}}}$ & $\overline{H_{o p, t-1}}$ & $\overline{H_{s r, t-1}}$ \\
\hline \multirow{7}{*}{ No-spillover } & Oil price & 6.49 & 0.18 & - & 0.64 & - \\
\hline & Real stock returns & 0.65 & - & 0.18 & - & 0.79 \\
\hline & $A(2,1)$ & \multicolumn{5}{|c|}{0.05} \\
\hline & $\Phi(1,1)$ & \multicolumn{5}{|c|}{1.22} \\
\hline & $\Phi(1,2)$ & \multicolumn{5}{|c|}{$0.41(0.12)$} \\
\hline & $\Phi(2,1)$ & \multicolumn{5}{|c|}{$-0.20(0.015)$} \\
\hline & Log-likelihood & \multicolumn{5}{|c|}{-1655.502} \\
\hline
\end{tabular}

Table 3.10: The coefficient estimates for the subsample 1987:6-2011:7. Note: $\epsilon_{o p, t-1}^{2}$ and $\epsilon_{s r, t-1}^{2}$ are the components of $\operatorname{diag}\left(\epsilon_{t-1} \epsilon_{t-1}^{\prime}\right)$ for the oil price and stock returns, respectively; $H_{o p, t-1}$ and $H_{s r, t-1}$ are the components of $\operatorname{diag}\left(H_{t-1}\right)$ for the oil price and stock returns, respectively. GARCH coefficients are provided in the first two rows, below which the estimate of $A(2,1), \Phi(1,1), \Phi(1,2), \Phi(2,1)$, and the log-likelihood value are presented. The asymptotic left side $p$-values of the estimates of $\Phi(1,2)$ and $\Phi(2,1)$ are also included in the parentheses. 


\section{$4 \quad$ Conclusion}

The contribution of this dissertation to the oil price-economy literature mainly lies in two aspects. First, it complements the existing oil price shock decomposition studies by using the gold price to capture a wider range of speculation. While in the existing literature the speculation proxied by oil futures price or oil inventory data mainly captures the speculation on the oil market, the use of gold price proxies speculation that has a wider range including, for example, speculations on future economic prospects. Studying a wider range of speculation is important to better understand the oil price-economy relationship, since the importance of crude oil is not limited on the oil market, but has a wide implications on different aspects of economic activities. The results confirm that speculation has a critical role in driving the changes of the oil price and moreover, the speculative component of an oil price shock has a negative impact on macroeconomic growth. However, the impact on inflation does not seem to be as important. This results also have policy implications, as we discussed, that if the speculation can be better regulated, the economic growth may be more stable during the oil price fluctuations.

Second, the dissertation studies the oil price-stock market relationship in a different angle. We use a GARCH-M VAR model to capture the volatility spillover between the oil market and the stock market and the potential impact of oil price volatility on the stock returns level. We detected a significant structural break between May and June 1987. Before the break, there was a unidirectional volatility spillover from the stock market to the oil market, but oil price volatility does not depress stock returns. 
In contrast, oil price volatility becomes more important after the break, showing a significant negative impact on stock returns level. However, the volatility spillover between the two markets vanished after the break. We also discussed the potential causes for the break, arguing that three major events could have contributed to the structural change. They are the OPEC collapse in late 1985, but with a extended effect to 1987; the Tax Reform Act in 1986 that depressed the motivation for investors; and, to a lesser extent, the stock market crash in October 1987. This study helps understand the evolution of the oil price-stock market relationship by looking at a longer time frame than existing literature, and the results can also shed lights on asset pricing and other related areas.

In summary, this dissertation studies two important aspects in the oil price literature by improving the understanding of the oil price-macroeconomy relationship and offering a different angle of the oil price-stock market relationship. For the oil price decomposition, our focus is mainly lag-viewed, or, we focus primarily on the past information. However, concurrent information can be highly useful, and decomposition methods based on modeling contemporaneous information can certainly improve our understanding about the implications of oil price fluctuations. One can also consider using other measures to capture the volatility, such as the forward looking traded option prices. ${ }^{1}$ In addition, our study uses the S\&P 500 Index to calculated stock returns; a study based on the stock returns for different sectors can also help us obtain more insights about the oil price-stock market relationship. Therefore, different improvements are yet possible, and research related to these topics may be carried out in future studies.

\footnotetext{
${ }^{1}$ See, for example, Black and Scholes (1973).
} 


\section{References}

Black, F. and Scholes, M. (1973). The Pricing of Options and Corporate Liabilities.

Journal of Political Economy, 8, 637-654. 


\section{VITA}

Junchuan Jesse Zeng was born on January 13, 1983 in Lanzhou, Gansu, China. He attended Lanzhou No. 1 High School. After several years of educational endeavors, he received the following degrees: B.A. in Economics from Lanzhou University, Lanzhou, Gansu, China (2005); M.A. in Economics from the University of Missouri (2009); M.A. in Statistics from the University of Missouri (2012); and will receive a Ph.D. in Economics from the University of Missouri (2013). From 2003 to 2004, he was a visiting student through the YOUC program at Otaru University of Commerce in Otaru, Hokkaido, Japan. He has been married to Ye Chen since 2011. Upon completion of his Ph.D., he will join JPMorgan Chase \& Co. in Wilmington, Delaware. 